\title{
Las pesquerías de crustáceos decápodos en el litoral de la República Argentina*
}

\author{
Enrique E. Boschi \\ Consejo Nacional de Investigaciones Científicas y Técnicas \\ Instituto Nacional de Investigación y Desarrollo Pesquero y Universidad de Buenos Aires \\ Casilla de Correo 175, 7600 Mar del Plata, Argentina
}

RESUMEN. Se analiza y se resume toda la información disponible sobre las pesquerías de crustáceos Decápodos comerciales del Mar Epicontinental Argentino y del talud contiguo. En la actualidad son cinco las especies que tienen valor comercial. Dos anomuros: Lithodes santolla (centolla) y Paralomis granulosa (centollón), dos peneidos: Pleoticus muelleri (langostino) y Artemesia longinaris (camarón) y un braquiuro: Ovalipes trimaculatus (cangrejo nadador).

Mediante campañas y viajes a distintas regiones donde se hallan y explotan estos crustáceos se dispone de una importante información biológico-pesquera, relativa a las épocas y zonas de reproducción, crecimiento, reclutamiento, áreas de concentraciones pescables, fluctuaciones, etc, lo que ha permitido recomendar un ordenamiento adecuado en la pesquería de alguna de ellas. Se destaca las poblaciones de langostino del litoral patagónico, por ser el recurso de mayor importancia.

Desde 1980 ha crecido la extracción de langostino en forma significativa, con fluctuaciones anuales, llegando en algunos años a volúmenes de desembarques de más de 25.000 tm lo que sobrepasa los 100 millones de dólares americanos en valor de exportación.

Palabras claves: crustáceos, decápodos marinos, pesquerías, Atlántico sudoeste, Argentina.

\section{Fisheries of marine decapod crustaceans in Argentina*}

\begin{abstract}
The existent information on the fisheries of Decapod Crustaceans on the continental shelf and slope off Argentina (South West Atlantic Ocean) is resumed and analysed.

At the present five species of Decapoda have commercial value two anomurans: Lithodes santolla (Southern king crab) and Paralomis granulosa (False king crab), two peneids: Pleoticus muelleri (Argentine red shrimp) and Artemesia longinaris (Argentine stiletto shrimp) and one brachyuran Ovalipes trimaculatus (swimming crab).

Scientific cruises and expeditions were performed to different regions of the sea, where these crustaceans are exploited. It was possible to obtain important biological and fishery informations on these species, in relations to areas and seasons of the reproduction, growth, recruiment, fishery concentration, etc, which allowed to recommend management of these resources. The most importan one is the patagonian stock of the P. muelleri. Since 1980, landing of this shrimp have increased significantly and in some years, reached $25.000 \mathrm{mt}$. This represents about $100 \mathrm{millon}$ US dollars, as the value for exportation.
\end{abstract}

Key words: crustaceans, marine decapoda, fishery, south west Atlantic ocean, Argentina.

\section{INTRODUCCION}

El número de especies de crustáceos decápodos que se explota en el litoral marítimo de la Argentina es de sólo cinco. De éstas únicamente el langostino (Pleoticus muelleri) se extrae en cantidades significativas. Las cuatro restantes que son: camarón

* Contribución INIDEP Nº 1010
(Artemesia longinaris), centolla (Lithodes santolla), centollón (Paralomis granulosa) y cangrejo nadador (Ovalipes trimaculatus) se las pesca en volúmenes relativamente bajos, en particular la última mencionada, no obstante ello, el valor de dicho recurso permite mantener una cierta actividad extractiva. 
En este trabajo se resume toda la información publicada y otros datos accesibles al autor, aunque mucha documentación de las últimas campañas aún no ha sido publicada ni se dispone de un análisis e interpretación de conjunto de las mismas. Naturalmente es sobre el langostino patagónico que el Instituto Nacional de Investigación y Desarrollo Pesquero (INIDEP) ha destinado los mayores esfuerzos de investigación en los últimos años, así como el Centro Austral de Investigaciones Científicas (CADIC), de Ushuaia, sobre la centolla y centollón del Canal Beagle. No obstante ello, de ninguna especie se dispone de un conocimiento acabado, por lo que las investigaciones deben continuar para complementar y ahondar los trabajos efectuados y proseguir con su monitoreo. Todo ello permite ofrecer a las autoridades responsables de la administración de los recursos pautas adecuadas de manejo y a los empresarios y pescadores elementos de valiosa orientación para el desarrollo de sus actividades.

\section{LAS PESQUERIAS ARGENTINAS DE CRUSTACEOS}

De los valores consignados en las estadísticas oficiales de desembarques de los últimos quince años, se pueden observar fluctuaciones pronunciadas en algunas especies. El caso más espectacular lo constituye el langostino del litoral patagónico que desde algunas pocas toneladas en 1979, los desembarques declarados llegaron en 1992 a cerca de 25.000 tm, y para 1994 se consignan desembarques de 15.826 tm (Tabla 1). Debido al alto valor de este crustáceo en los mercados internacionales, se ha transformado en el producto principal de las exportaciones pesqueras argentinas, con un valor de 134,1 millones de dólares, lo que significó el 18,4\% de los 725,7 millones de productos exportados en 1994, si bien el mercado estuvo algo deprimido en los últimos años debido a la gran oferta de camarones peneidos a nivel mundial. Para ese mismo año, las exportaciones de langostino se destinaron a 14 países, siendo los principales compradores España, Japón, Italia y Holanda.

Se debe consignar por otra parte, que el langostino no es la primera vez que muestra oscilaciones en su abundancia en distintas áreas y épocas de capturas en el litoral de la Argentina (Boschi, 1986), Sin embargo, en los últimos años la presencia del recurso, en volúmenes importantes en las áreas de pesca patagónica, permite suponer que las medidas regulatorias establecidas sobre su pesquería han sido adecuadas (Boschi, 1989).

A parte de ello se suele registrar en las partes de desembarques de la flota de congeladores y factorías capturas de "langostino" sin una precisa ubicación, en áreas apartadas de la distribución geográfica conocida, más al sur, a la latitud de Tierra del Fuego o en aguas que sobrepasan la isobata de $200 \mathrm{~m}$. Estos registros de capturas posiblemente se traten de alguna especie de camarón Caridea de aguas más profundas, dentro de las especies consideradas de interés potencial. Por otra parte en las estadísticas nacionales de captura suele aparecer en el rubro "otros crustáceos" una variable cantidad de desembarques de especies que no han sido adecuadamente identificadas.

Tabla 1. Desembarques de las cinco especies principales de crustáceos marinos de Argentina, entre 1979 y 1994 (en tm)

Table 1. Landing of the five main species of marine crustaceans of Argentina, between 1979 and 1994 (in mt).

\begin{tabular}{|lrrrrrrrrrrrrrrr|r|}
\hline \multirow{2}{*}{ ESPECIE } & \multicolumn{11}{c|}{ AÑ } \\
& 1979 & 1980 & 1981 & 1982 & 1983 & 1984 & 1985 & 1986 & 1987 & 1988 & 1989 & 1990 & 1991 & 1992 & 1993 & 1994 \\
\hline Langostino & 4 & 727 & 2.616 & 7.667 & 18.975 & 22.994 & 9.836 & 6.768 & 2.142 & 17.800 & 11.600 & 9.631 & 8.219 & 24.397 & 17.645 & 15.826 \\
Camarón & 48 & 74 & 114 & 147 & 314 & 125 & 430 & 211 & 294 & 211 & 177 & 197 & 149 & 380 & 185 & 215 \\
Centolla & 62 & 77 & 174 & 203 & 179 & 200 & 188 & 194 & 153 & 194 & 120 & 125 & 114 & 143 & 158 & 295 \\
Centollón & 20 & 21 & 6 & 52 & 78 & 105 & 163 & 154 & 103 & 154 & 121 & 150 & 189 & 37 & 27 & 151 \\
Cangrejo & 5 & 10 & 6 & 5 & 14 & 4 & 10 & 11 & 4 & 11 & 11 & 20 & 17 & 20 & 27 & 17 \\
\hline
\end{tabular}

Fuente: Datos de la Dirección Nacional de Pesca y Acuicultura, Secretaría de Agricultura, Pesca y Alimentación. 
En cuanto al centollón, se consigna su presencia en las estadísticas a partir de 1975 con desembarques esporádicos. En 1982 las capturas se elevaron en el sector argentino del Canal Beagle en razón de que comienza su industrialización, debido a la acentuada disminución de la centolla en esa misma región.

\section{Centolla y centollón}

La pesca de centolla y centollón se realizó en aguas jurisdiccionales de Argentina, principalmente en el Canal Beagle, siendo en esta región una pesquería permanente y sujeta a reglamentación específica. A partir de los últimos cuatro o cinco años las extracciones de centolla en sectores del golfo San Jorge se han incrementado considerablemente, con puertos de desembarque en Comodoro Rivadavia y Caleta Córdoba, sobrepasando los volúmenes registrados para el Canal Beagle (Tierra del Fuego) (Fig. 1 y Tabla 2). El resto de las capturas, que son de poco volumen, la realizan los barcos arrastreros de altura, que obtienen centolla en los fondos de pesca de merluza. Se debe destacar que los mayores desembarques de ambas especies se verifican en Chile, en la amplia área de pesca de la región magallánica y fueguina, con $1666 \mathrm{tm}$ de centolla y $2221 \mathrm{tm}$ de centollón, consignados para 1994 (SERNAPESCA, 1995).

La pesca de la centolla en el sector argentino del Canal Beagle se realiza desde hace cerca de 50 años. Las primeras capturas se llevaron a cabo empleando redes de enmalle que se fondeaban principalmente en la Bahía de Ushuaia y áreas adyacentes. El centollón que se capturaba conjuntamente con la centolla, hasta hace pocos años se desechaba, pero debido a la disminución de los efectivos de centolla, a partir de 1982 comenzaron a ser industrializada en Ushuaia capturas provenientes de

Tabla 2. Desembarques totales de centolla por puerto, entre 1990 y 1994 (en tm).

Table 2. Total landings of antarctic king crab by port, between 1990 and 1994 (in $\mathrm{mt}$ ).

\begin{tabular}{|lccccc|}
\hline \multirow{2}{*}{ Puerto } & \multicolumn{6}{c|}{ Año } \\
& $\mathbf{1 9 9 0}$ & $\mathbf{1 9 9 1}$ & $\mathbf{1 9 9 2}$ & $\mathbf{1 9 9 3}$ & $\mathbf{1 9 9 4}$ \\
\hline Mar del Plata & 0,225 & - & 0,015 & - & - \\
C. Rivadavia & 3,05 & 3,98 & 10,06 & 14 & 94,3 \\
Rawson & - & 0,25 & - & - & - \\
Caleta Córdoba & 32,89 & 48,49 & 62,23 & 62,23 & 132,1 \\
Ushuaia & 89,23 & 61,04 & 69,71 & 69,71 & 56,0 \\
\hline
\end{tabular}

la zona, igualando en algunos años los rendimientos de centolla.

En cuanto a la modalidad de extracción, el único arte de pesca permitido para estos crustáceos en el Canal Beagle es la trampa. Rige una veda permanente para la pesca de ambas especies entre el $1^{\circ}$ de noviembre y el $1^{\circ}$ de enero en el sector argentino del Canal Beagle, hasta Punta Falsa. Las hembras deben ser devueltas al mar porque está prohibida su pesca durante todo el año y sólo se permite industrializar machos mayores de $12 \mathrm{~cm}$ de ancho de caparazón en el caso de la centolla y para el centollón, machos de un ancho de caparazón mayor de $9 \mathrm{~cm}$. Se han introducido además distintos períodos de veda, de acuerdo con el estado del recurso, prohibiéndose la captura de centolla en el área comprendida entre el límite con Chile y Punta Segunda. Además, en los últimos años surgió una pesca artesanal autorizada, llevada a cabo por pescadores aislados que utilizan dos o tres trampas y preparan productos congelados para venta local.

En general, el stock de centolla en el sector argentino del Canal Beagle hasta el frontón Gable ha disminuido permanentemente y se halla en estado se sobreexplotación, con una alarmante disminución en el porcentaje de hembras ovígeras (sólo el 38\% del total de hembras capturadas en las áreas comprendidas entre Bahía Saenz Valiente y Bahía de Ushuaia) y una caída constante de los rendimientos, según observaciones realizadas en 1994 por la Dirección General de Recursos Naturales de Ushuaia.

Centolla. Los estudios sobre la biología pesquera de la centolla se iniciaron en Ushuaia en 1973, mediante algunos muestreos obtenidos de capturas con redes enmalladoras y trampas (Scelzo et al., 1974). En 1974 se llevó a cabo una campaña de investigación pesquera al Canal Beagle, con el BIP "Cruz del Sur", del Proyecto de Desarrollo Pesquero de la FAO en la Argentina. En esa oportunidad se realizaron numerosas mediciones de centolla y centollón y se concretaron las primeras marcaciones de esta especie en dicha región (Fenucci et al., 1974).

Los trabajos más continuados sobre la biología pesquera de la centolla, comenzaron en el Canal Beagle, mediante un convenio celebrado entre el exInstituto de Biología Marina de Mar del Plata, el Proyecto de Desarrollo Pesquero de la FAO en la Argentina y el entonces Territorio Nacional de Tierra del Fuego, Antártida e Islas del Atlántico Sur, 


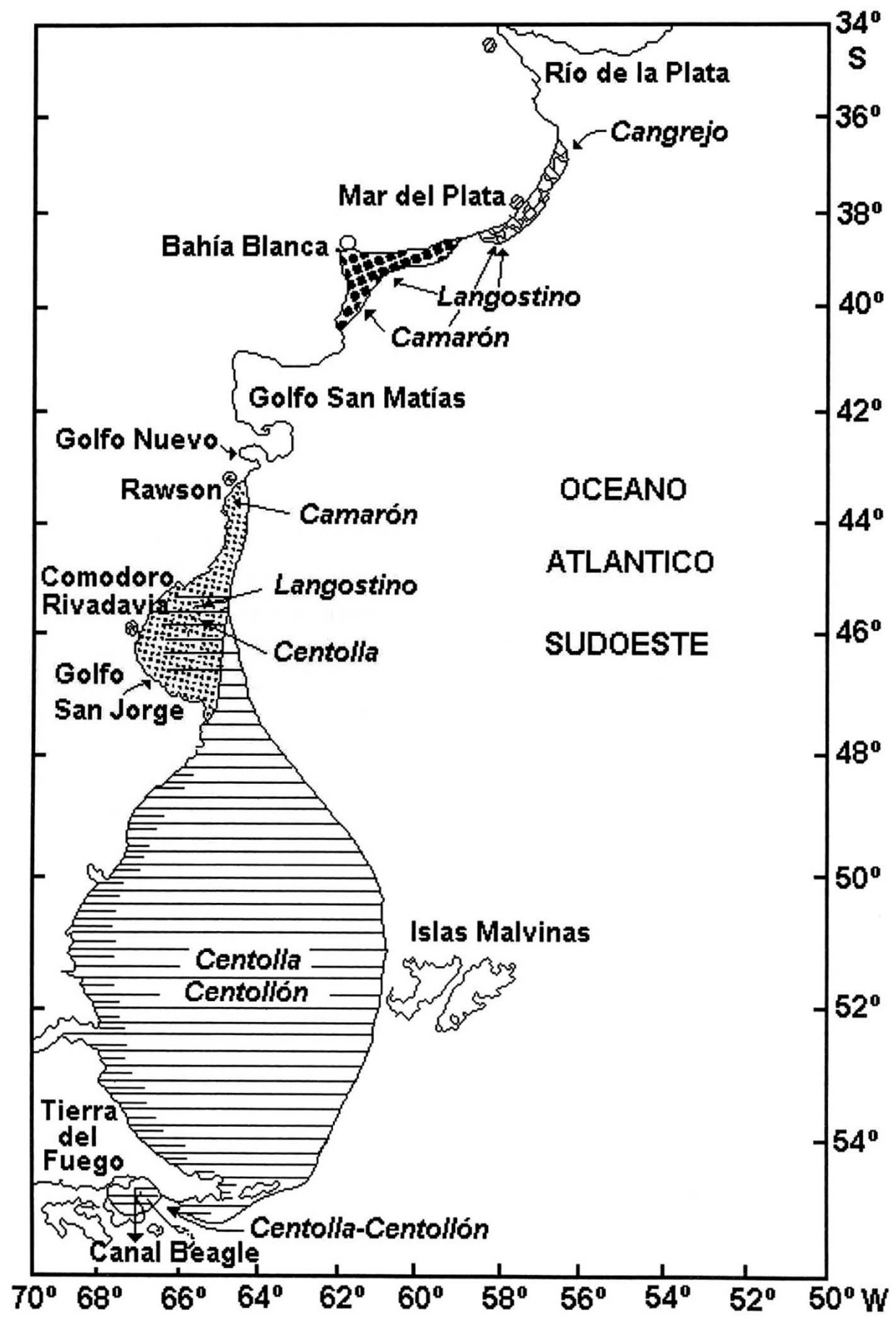

Figura 1. Zonas habituales de pesca comercial del langostino (Pleoticus muelleri), centolla (Lithodes santolla), centollón (Paralomis granulosa), camarón (Artemesia longinaris) y cangrejo nadador (Ovalipes trimaculatus), frente al litoral de la República Argentina.

Figure 1. Location of traditional commercial fishing areas for Argentine red shrimp (Pleoticus muelleri), southern king crab (Lithodes santolla), false king crab (Paralomis granulosa), Argentine stiletto shrimp (Artemesia longinaris) and swimming crab (Ovalipes trimaculatus), along the coast of Argentina. 
del que surgieron cuatro informes técnicos (Boschi et al., 1975, 1976).

El mayor impulso a los estudios sobre aspectos de la biología y evaluación del recurso centolla del Canal Beagle, se realizó en 1980 y 1981 mediante un convenio entre el INIDEP y las tres empresas dedicadas en esos años a la extracción de la centolla en esa región, con auspicio del entonces Territorio de Tierra del Fuego, Antártida e Islas del Atlántico Sur.

A partir de ese convenio, un grupo de biólogos concurrió mensualmente a la región realizando viajes de un día de duración en las embarcaciones pesqueras, con el fin de recoger distintos tipos de información biológica de la centolla y de su pesquería. De los resultados de esos estudios surgieron numerosos datos del ciclo vital de la especie, estimaciones de biomasa, así como los fundamentos para la ordenación de la pesquería (Boschi et al., 1984; Bertuche et al., 1985; Vinuesa, 1984).

Luego de ese período, en 1993, se concretó otro convenio que posibilita la continuación de las investigaciones, en razón del estado de colapso de la pesquería de centolla en la región, que incluye el centollón y estudios sobre la selectividad de las trampas en las capturas comerciales.

La comparación de los distintos valores medios de tallas (largo de caparazón) de la centolla, desde los primeros años de estudios en 1974, hasta los últimos muestreos realizados de capturas en la Bahía de Ushuaia, en 1995, se observa una constante declinación de los tamaños medios, tanto de machos como de hembras, en las centollas capturadas (Fig. 3). Estos valores oscilaron para machos entre 114,4 mm Lc, en 1974 y 95,7 mm Lc, en 1989 (Tabla 3) y se indican tallas menores aún para 1994, particularmente en hembras.

Los cálculos de biomasa obtenidas a partir de datos de investigaciones previas, desde 1975, también demuestran la declinación numérica del recurso (Bertuche et al., 1990). Estas estimaciones se efectuaron analizando los resultados de las investigaciones correspondientes a los trimestres junio-julio y agosto de 1975, 1981, 1988 y 1989 para el área de la Bahía de Ushuaia (Area III según la separación en áreas establecida previamente, Boschi et al., 1984) y en 1981, 1988 y 1989, en la Bahía Golondrina (Area II).

La disminución de la abundancia del recurso también se pone de manifiesto por los menores rendimientos de captura por trampa (Bertuche et al., 1990), entre 1975 y 1989 (Tabla 4). Para 1995 los rendimientos siguieron disminuyendo, con un valor promedio total de captura por trampa de 1,25 centollas (DGRN, Ushuaia, 1995). No se dispone de datos de biomasa en los últimos años en los que se realizaron investigaciones biológicas en esa región.

Vinuesa y Lovrich (1992) han realizado investigaciones biológicas de manera continua sobre la centolla en el Canal Beagle, verificando la escasez de juveniles de esta especie en áreas donde normalmente existían, lo cual permite presumir que el reclutamiento de alguna clase anual fue muy

Tabla 3. Valores medios de largo de caparazón de centolla machos y hembras en el Canal Beagle (Bahía de Ushuaia e Islas Bridges), desde el comienzo de los estudios biológicos en 1974 hasta 1989.

Table 3. Mean values of male and female antarctic king crabs'from Beagle Channel (Bay of Ushuaia and Bridges Islands), since the beginning of the biological studies in 1974 through 1989.

\begin{tabular}{|lccccc|}
\hline Lugar & & & \multicolumn{4}{c|}{$\begin{array}{c}\text { Longitud Media } \\
\text { del Caparazón }\end{array}$} \\
\hline Bahía de Ushuaia & 1974 & Enmalladora & 114,4 & - & Scelzo et al., 1974 \\
Bahía de Ushuaia & 1975 & Trampa & 108,2 & 93,5 & Boschi et al., 1975 \\
Bahía de Ushuaia & 1978 & Trampa & 102,8 & 95,8 & Fenucci, 1978 \\
Bahía de Ushuaia & 1979 & Trampa & 101,5 & 95,2 & Bertuche, 1979 \\
Bahía de Ushuaia & 1981 & & & & \\
Bahía de Ushuaia & 1982 & Trampa & 100,5 & 92,2 & Boschi et al., 1984 \\
Bahía de Ushuaia & 1988 & Trampa & 96,3 & 83,5 & Bertuche et al., 1981 \\
& 1989 & Trampa & 95,7 & 83,2 & Bertuche et al., 1989 \\
\hline
\end{tabular}


pobre, situación que se podrá verificar cuando la clase sea reclutada por el arte de pesca. La escasez mencionada no será fácil de comprobar debido al lento crecimiento de la centolla en las edades de cinco años o más, lo que determina seguramente que exista, dentro de la curva de distribución de cada cohorte, una marcada superposición de animales con igual talla pero con edades diferentes. Además, los mismos autores certifican una alarmante disminución de hembras con huevos adheridos a las patas abdominales en el período normal del desarrollo embrionario, con sólo 5 y $7 \%$ en 1987 y 1988 respectivamente, del total de hembras estudiadas en las áreas de la Península de Ushuaia y
Bahía Golondrina. Habría que verificar si esas hembras son virginales e ingresan por primera vez a los fondos de pesca, por ausencia de las adultas, o si hay escasez de machos de talla adecuada para el acoplamiento.

El continuo desembarque de machos menores de la talla legal de $120 \mathrm{~mm}$ de ancho de caparazón, así como la retención en las capturas de hembras, situación que se ha acentuado en los últimos años (Vinuesa y Lovrich, 1992) ha llevado al recurso a un estado de evidente sobreexplotación aún con la incorporación del centollón a la pesquería a partir de 1982.

Tabla 4. Valores medios de captura por trampa (CPUE) de centolla de tres áreas de pesca del Canal Beagle, en el transcurso de tres años de estudio, según Bertuche et al. (1989).

Table 4. Mean catch per trap values (CPUE) of antarctic king crab of three fishing areas of the Beagle Channel, during three years of study, according to Bertuche et al. (1989).

\begin{tabular}{|c|c|c|c|c|c|c|c|c|c|}
\hline \multirow[t]{2}{*}{ AÑO } & \multicolumn{3}{|c|}{ BAHIA GOLONDRINA } & \multicolumn{3}{|c|}{ BAHIA DE USHUAIA } & \multicolumn{3}{|c|}{ PUNTA REMOLINOS } \\
\hline & $\begin{array}{l}\text { CPUE } \\
\text { media }\end{array}$ & DS & $\mathbf{N}^{\circ}$ viajes & $\begin{array}{l}\text { CPUE } \\
\text { media }\end{array}$ & DS & $\mathbf{N}^{\circ}$ viajes & $\begin{array}{l}\text { CPUE } \\
\text { media }\end{array}$ & DS & $\mathbf{N}^{0}$ viajes \\
\hline 1975 & 11,1 & 5,5 & 9 & 12,0 & 5,8 & 7 & - & - & \\
\hline 1981 & 8,9 & 4,0 & 27 & 9,6 & 3,9 & 29 & 11,5 & 5,5 & 10 \\
\hline 1989 & 5,5 & 2,9 & 23 & 4,9 & 3,0 & 20 & 7,3 & 3,8 & 12 \\
\hline
\end{tabular}

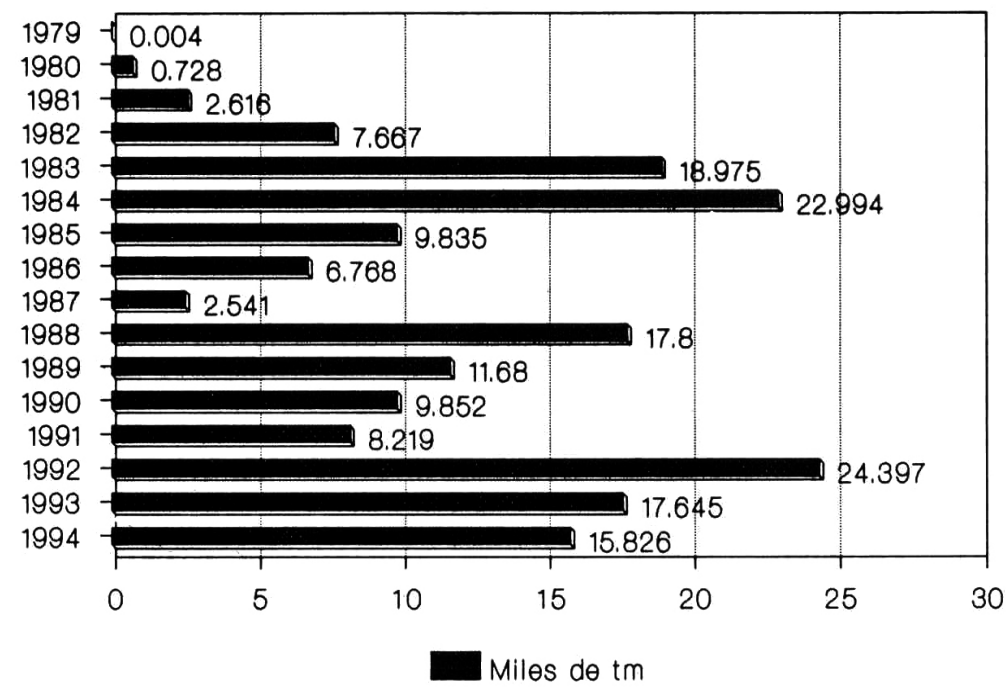

Figura 2. Desembarques anuales de langostino (Pleoticus muelleri) en Argentina, entre 1979 y 1994.

Figure 2. Annual landings of Argentine red shrimp (Pleoticus muelleri), between 1979 and 1994. 


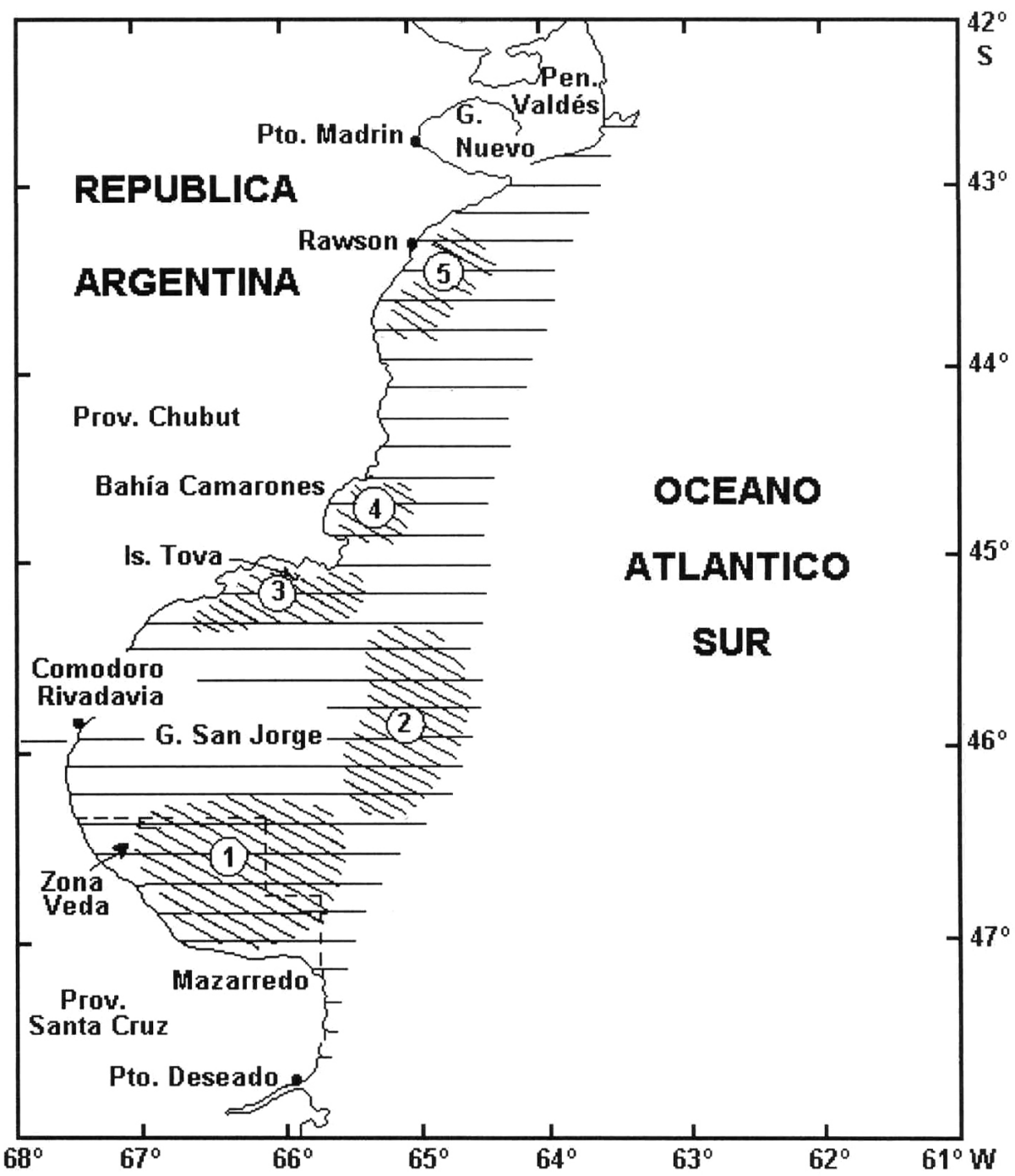

Figura 3. Areas de distribución del langostino (Pleoticus muelleri) juvenil y adulto, en el litoral patagónico (rayado horizontal) y zonas tradicionales de pesca (rayado oblicuo). En la zona sur se indica con línea interrumpida el área de veda permanente para la pesca comercial.

Figure 3. Distribution of juvenile and adult Argentine red shrimp (Pleoticus muelleri) along the coast of Patagonia (horizontal lines), and traditional fishing areas (oblique lines). The dotted line in the southern zone indicates the area permanently closed for the commercial fishery.

Centollón. Esta especie se pesca conjuntamente con la centolla en el Canal Beagle y es la segunda en importancia en las capturas comerciales de la región (Tabla 1). Las mayores tallas analizadas por Lovrich (1991) fueron de $88 \mathrm{~mm}$ Lc para hembras y $115 \mathrm{~mm}$ Lc para machos de un total de 1.198 ejemplares estudiados, en muestreos realizados en 1989 y 1990, ade- más del estudio de crecimiento de juveniles (Lovrich y Vinuesa, 1995). El ciclo reproductivo de esta especie abarca dos años y los huevos son llevados por las hembras durante 18 y 22 meses (Lovrich y Vinuesa, 1993; Lovrich,1994), lo que contrasta con el de la centolla que es anual. Según estudios más recientes (DGRN, Ushuaia, 1995) las 
tallas medias del centollón del Canal Beagle oscilan entre $86,2 \mathrm{~mm}$ para machos y $75,7 \mathrm{~mm}$ para hembras.

El interés por el centollón en el Canal Beagle surgió básicamente por la acentuada disminución de los efectivos de centolla en la región. Los desembarques registrados en las estadísticas provienen en su gran mayoría del Beagle y desde 1981 hasta 1992 han variado entre un mínimo de 6 tm en 1981 y un máximo de 189 tm en 1991. Los datos de 1993 demuestran un brusco descenso de su captura, a sólo $27 \mathrm{tm}$, debido al menor interés de la industria local en la especie. En 1994 las capturas se incrementaron nuevamente, llegando a $151 \mathrm{tm}$.

En razón del ciclo reproductivo bienal, baja frecuencia de muda y número reducido de huevos por hembra, con una fecundidad que varía entre 1.440 a 8.100 para animales entre 63 y $85 \mathrm{~mm}$ de Lc, la pesquería de esta especie requiere de un ordenamiento especial. Las reglamentaciones actuales autorizan solamente la captura de machos mayores de 90 mm de ancho de caparazón ( $80 \mathrm{~mm} \mathrm{Lc)} \mathrm{y} \mathrm{prohibe}$ la extracción de hembras permanentemente, pero con poco acatamiento a la misma (Lovrich y Vinuesa, 1992). El tamaño mínimo legal para la captura de machos de centolla y centollón, lo establece la provincia de Tierra del Fuego, Antártida e Islas del Atlántico Sur, mediante la Ley 114/93.

\section{La pesquería en el litoral patagónico}

La centolla del litoral patagónico ha sido pescada en pequeñas cantidades y sólo en los últimos años han aumentado los desembarques provenientes de capturas del golfo San Jorge. Por esta razón, el conocimiento biológico de estas concentraciones es menor que el de las poblaciones del Canal Beagle. En cuanto al centollón, las capturas en el litoral patagónico son muy reducidas, particularmente en el golfo San Jorge por lo que la información biológica de esta especie en esa región es escasa.

Hace años, en algunas áreas localizadas frente a Santa Cruz, en el paraje denominado La Angelina, a unos $34 \mathrm{~km}$ al noreste de Río Gallegos, sobre la Bahía Grande, se extraía centolla, en noviembre y diciembre, empleando enmalladoras, en una playa de cinco mil $\mathrm{m}$ de largo y dos mil $\mathrm{m}$ de ancho. Las faenas se realizaban durante la bajamar, aprovechando las amplias diferencias de mareas, de cerca de $10 \mathrm{~m}$. Las cantidades capturadas oscilaban entre 4.000 y 9.000 ejemplares por temporada.

En los trabajos realizados en 1973 en esa loca- lidad (Scelzo et al., 1974) se obtuvieron datos de tallas de 751 ejemplares, de los cuales 550 correspondieron a machos y 201 a hembras. El tamaño de los machos osciló entre 80 y $150 \mathrm{~mm}$ de Lc, con una talla media de $118,8 \mathrm{~mm}$ y las hembras entre 60 y $110 \mathrm{~mm}$, con una media de $80,3 \mathrm{~mm}$ de Lc. En la temporada de pesca de 1973 (11 de noviembre al 26 de diciembre), se emplearon $1880 \mathrm{~m}$ de redes diariamente y se capturaron 7.250 centollas de ambos sexos, con rendimientos en número de 4-9 centollas/cada $100 \mathrm{~m}$ de red/día, y en peso ponderado de machos y hembras, estimado entre 4,0 y 9,0 . Estos valores resultan útiles con el fin de compararlos con observaciones más recientes.

En los últimos tres o cuatro años se hallaron excelentes caladeros de centolla de buena talla (100$120 \mathrm{~mm}$ de Lc) en sectores internos y en la boca del golfo San Jorge. Las capturas actuales más importantes de Argentina se logran en ese golfo, con barcos arrastreros que desembarcan en Comodoro Rivadavia y Caleta Córdoba (Tabla 2). Según las estadísticas de 1994, se obtuvieron en esos puertos 94,3 y 132,1 tm respectivamente. En toda la región de pesca de merluza también se producen capturas esporádicas de centolla que no sobrepasan las 20 tm anuales.

La centolla del golfo San Jorge fue estudiada por Vinuesa (1985), destacándose el menor tamaño de la especie de esta zona, comparada con la del Canal Beagle. Para aquella época el análisis de cerca de 2.000 ejemplares dieron una talla media más pequeña comparada con las que se pescan actualmente en el mencionado golfo, en machos $\mathrm{Lc}=95,2$ $\mathrm{mm}$ y en hembras Lc $=69,1 \mathrm{~mm}$. Además, estos ejemplares tienen un tono rosado, distinto al rojo-violáceo oscuro de las poblaciones del Beagle. Por otra parte, existen algunas otras diferencias morfológicas y biológicas con las de esta región. El período de muda en las hembras, según las observaciones de Vinuesa (1985), se inicia a fines de octubre, intensificándose en noviembre, un mes antes que en el Beagle. De todas maneras, toda esta información preliminar y de años anteriores, deberá ser actualizada con los nuevos trabajos en curso.

Un hecho interesante es el aumento en los últimos años de las capturas de centolla adultas en el golfo San Jorge. Actualmente el INIDEP está llevando a cabo estudios biológico-pesqueros de la centolla de esa región, por lo cual se dispondrá de resultados accesibles a corto plazo.

Por otra parte, se pensó que los efectivos de 
centolla en áreas abiertas de la plataforma patagónica, debían ser más abundantes, por tal razón se realizaron varios viajes exploratorios en distintas épocas, alistando barcos pesqueros preparados para la extracción de centolla, con el fin de localizar altas concentraciones de este crustáceo. El primer viaje con esos fines, fue el del "Tayo Maru 22", que estaba equipado con redes enmalladoras y redes de arrastre de fondo. Ese barco operó entre el 30 de diciembre de 1958 y el 4 de marzo de 1959 (Angelescu, 1960). En general, los resultados de este viaje fueron modestos. El total capturado en los litorales de Santa Cruz y Tierra del Fuego, con red de enmalle, fue de cerca de 2.000 centollas. El tamaño medio de una muestra de 69 ejemplares examinados durante la campaña fue de $119 \mathrm{~mm}$ de ancho de caparazón, lo que equivale a unos 108 mm de Lc.

Con el barco "Shinmei Maru 12" se pescó frente a las costas de Santa Cruz durante el 8 de noviembre y 3 de diciembre de 1972 , con redes enmalladoras, entre las latitudes. $50^{\circ} 55^{\prime} \mathrm{S}$ y $52^{\circ} 20^{\prime} \mathrm{S}$ y las longitudes $67^{\circ} 59^{\prime} \mathrm{W}$ y $69^{\circ} 07^{\prime} \mathrm{W}$, a una profundidad de 6 y $71 \mathrm{~m}$, capturándose $11 \mathrm{tm}$ de centolla. Se utilizaron en total unos $20.000 \mathrm{~m}$ de redes enmalladoras durante 26 días de pesca. Los rendimientos dentro de las tres millas de la costa y en profundidades de 6 y $16 \mathrm{~m}$, oscilaron entre 2,08 y $1,30 \mathrm{~kg}$ de centolla, cada $100 \mathrm{~m}$ de red por día de pesca. En cambio, en aguas fuera de las 12 millas, en profundidades de 45 y $71 \mathrm{~m}$, los rendimientos fueron de 1,42 y 1,56 kg/100 m de red/día de pesca.

De las experiencias más destacadas realizadas en los últimos años por un barco fletado para la localización de centolla, se destaca los viajes del "Hoshin Maru 2". contratado especialmente por la empresa Santa Elena S.A.I.C. y autorizado por la entonces Secretaría de Agricultura, Ganadería y Pesca, para operar durante 1986. Los datos de los resultados de parte de estas campañas han sido facilitados por el Dr. L.B. Prenski (INIDEP).

El viaje del "Hoshin Maru 2" se extendió desde el 17 de febrero al 27 de noviembre de 1986 y se utilizaron trampas para la captura de centolla, se emplearon palangres para peces y poteras para el calamar. En este trabajo se consideran solamente los resultados sobre la centolla y centollón.

En la primera etapa de la campaña se investigaron las aguas costeras de Santa Cruz y Tierra del Fuego, así como la región del Banco Burdwood, frente a las islas Malvinas. El barco trabajó con ocho líneas de 180-200 trampas de tipo cónica en cada una de ellas, similares a las empleadas en el Canal Beagle. Debido al calado del barco no fue posible extender las experiencias en aguas someras, a menos de $8 \mathrm{~m}$ de profundidad. La máxima profundidad de pesca fue de $87 \mathrm{~m}$, que corresponde a aguas alejadas de la costa y al sur de las islas Malvinas.

Las capturas más exitosas, tanto de centolla como de centollón, se realizaron en marzo a profundidades entre 8 y $28 \mathrm{~m}$ frente a aguas costeras de la Tierra del Fuego (Isla Grande). En el lance 9 se lograron 208 centollas y 617 centollones. En el lance 10 se lograron 304 centollas y 303 centollones. En todas las capturas mencionadas sólo se pescaron ejemplares machos. Los rendimientos (CPUE) fueron bajos, salvo el lance 14 que dió un rendimiento de 6,2 centollones/trampa (Tabla 5). Las tallas de los ejemplares medidos en seis muestreos de centolla dieron valores medios que oscilaron entre 98,1 y 111,0 mm de Lc y en el centollón entre 85,2 y 92,0 mm de Lc (Tablas 6 y 7). En este caso particular, la captura por unidad de esfuerzo (CPUE) se define como el número de centollas y/o centollones capturados por líneas de trampas, constituidas por 180200 unidades, sin tener en cuenta el tiempo de pesca, ni sexo, ni el tipo de carnada, asumiendo que no se percibe incremento en la captura con más de 12 horas de pesca, por la desaparición de la carnada debido al consumo de la misma por la acción de pequeños crustáceos bentónicos (anfípodos/ isópodos).

En la región del Banco Burwood, los rendimientos fueron bajos, pero con tallas similares a las obtenidas en los muestreos costeros mencionados anteriormente. Las profundidades de calado de las líneas de trampas osciló entre 35 y 96 m y en las mejores capturas sólo se obtuvieron entre 25-30 centollas por línea.

Los resultados de la 5a y 6a etapas, en septiembre y octubre, fueron sumamente interesantes. Las capturas en la Bahía Grande mostraron una centolla de gran talla, con machos de hasta $138 \mathrm{~mm} \mathrm{Lc}$, $\mathrm{y}$ un peso de $1.580 \mathrm{~g}$ (Tabla 8). En las costas de Tierra del Fuego (Isla Grande) se obtuvieron machos de gran tamaño, de hasta $136 \mathrm{~mm}$ de Lc. En cambio entre las hembras de esta última localidad predominaron las medianas y pequeñas, de 71 y $97 \mathrm{~mm}$ de Lc (Bras Harriot, 1987, informe interno de resultados).

En la primera parte de la campaña (marzo), se capturaron solamente machos, lo que seguramente se debió a una agrupación espacial, diferente entre 
Tabla 5. Datos de captura de centolla y centollón, con trampas, de la campaña del $B / P<<H o s h i n ~ M a r u ~ 2>>$ en el litoral Patágonico, entre el $1^{\circ}$ y el 18 de marzo de 1986. Toda la captura fue de ejemplares machos.

Table 5. Traps catch data for centolla and centollón, of $B / P<<$ Hoshin Maru $2<<$ survey of the Patagonian littoral between the $1^{\circ}$ and $18^{\text {th }}$ of March 1986. All specimens in the catch were males.

\begin{tabular}{|c|c|c|c|c|c|c|c|c|c|c|c|c|c|c|}
\hline \multirow{2}{*}{$\begin{array}{c}\text { I } \\
\text { FECHA }\end{array}$} & \multirow{2}{*}{$\begin{array}{c}\text { LANCE } \\
\mathbf{N}^{\circ} \\
8^{*}\end{array}$} & \multicolumn{2}{|c|}{$\begin{array}{l}\text { LATITUD } \\
\text { INICIAL (S) }\end{array}$} & \multicolumn{2}{|c|}{$\begin{array}{l}\text { LONGITUD } \\
\text { INICIAL (W) }\end{array}$} & \multirow{2}{*}{$\begin{array}{c}\begin{array}{c}\text { PROF } \\
(\mathrm{m})\end{array} \\
21-23\end{array}$} & \multirow{2}{*}{$\begin{array}{c}\text { HORAS } \\
23\end{array}$} & \multirow{2}{*}{$\begin{array}{c}\begin{array}{c}\mathrm{N}^{\circ} \\
\text { TRAMPAS }\end{array} \\
200\end{array}$} & \multirow{2}{*}{$\begin{array}{c}\text { CAPTURA } \\
\mathrm{N}^{0} \\
64\end{array}$} & \multirow{2}{*}{$\begin{array}{c}\begin{array}{c}\text { CENTOLLA } \\
(\mathrm{kg})\end{array} \\
42.33\end{array}$} & \multirow{2}{*}{$\frac{\text { CPUE }}{}$} & \multirow{2}{*}{$\begin{array}{c}\begin{array}{c}\text { CAPTURA } \\
\mathrm{N}^{\mathbf{0}}\end{array} \\
5\end{array}$} & \multirow{2}{*}{$\begin{array}{c}\begin{array}{c}\text { CENTOLLON } \\
\text { P (kg) }\end{array} \\
1.94\end{array}$} & \multirow{2}{*}{$\begin{array}{r}\text { CPUE } \\
\text { (C/T) }\end{array}$} \\
\hline & & $53^{\circ}$ & $53^{\circ} 57^{\circ}$ & $67^{\circ} 35^{\circ}$ & $67^{\circ}$ & & & & & & & & & \\
\hline $2 / 3 / 86$ & $9 *$ & $53^{\circ}$ & $53^{\circ} 54^{\circ}$ & $67^{\circ} 22^{\circ}$ & $67^{\circ}$ & $8-18$ & 38 & 200 & 200 & 185.00 & 1.04 & 617 & 295.00 & 3.00 \\
\hline $2 / 3 / 86$ & 10 & $53^{\circ}$ & $53^{\circ} 47^{\circ}$ & $53^{\circ} 37^{\circ}$ & $67^{\circ}$ & $20-17$ & 19 & 200 & 304 & 171.50 & 1.52 & 303 & 104.00 & 1.51 \\
\hline $2 / 3 / 86$ & 11 & $53^{\circ}$ & $53^{\circ} 47^{\circ}$ & $67^{\circ} 33^{\circ}$ & $67^{\circ}$ & $8-24$ & 47 & 200 & 22 & 19.60 & 0.11 & 10 & 4.29 & 0.05 \\
\hline $3 / 3 / 86$ & $12^{*}$ & $53^{\circ}$ & $53^{\circ} 54^{\prime}$ & $67^{\circ} 22^{\prime}$ & $67^{\circ}$ & $25-23$ & 24 & 200 & 92 & 78.15 & 0.46 & 714 & 327.70 & 3.57 \\
\hline $3 / 3 / 86$ & $13^{*}$ & $53^{\circ}$ & $53^{\circ} 57^{\circ}$ & $67^{\circ} 20^{\circ}$ & $67^{\circ}$ & $15-22$ & 38 & 200 & 76 & 73.30 & 0.30 & 70 & 32.10 & 0.35 \\
\hline $3 / 3 / 86$ & 14 & $53^{\circ}$ & $53^{\circ} 52^{\circ}$ & $67^{\circ} 23^{\circ}$ & $67^{\circ}$ & $17-13$ & 23 & 200 & 88 & 71.50 & 0.44 & 1239 & 568.10 & 6.20 \\
\hline $3 / 3 / 86$ & 15 & $53^{\circ}$ & $53^{\circ} 55^{\circ}$ & $67^{\circ} 22^{\circ}$ & $67^{\circ}$ & $25-25$ & 23 & 200 & 110 & 93.14 & 0.55 & 275 & 168.70 & 1.30 \\
\hline $3 / 3 / 86$ & 16 & $53^{\circ}$ & $53^{\circ} 53^{\circ}$ & $67^{\circ} 25^{\circ}$ & $67^{\circ}$ & $22-20$ & 25 & 200 & 64 & 58.07 & 0.32 & 666 & 277.10 & 3.33 \\
\hline $4 / 3 / 86$ & 17 & $53^{\circ}$ & $54^{\circ} 00^{\circ}$ & $67^{\circ} 19^{\circ}$ & $67^{\circ}$ & $17-16$ & 37 & 190 & 18 & 15.44 & 0.09 & 19 & 8.46 & 0.10 \\
\hline $4 / 3 / 86$ & 18 & $53^{\circ}$ & $53^{\circ} 59^{\circ}$ & $67^{\circ} 20^{\circ}$ & $67^{\circ}$ & $22-18$ & 15 & 190 & 8 & 7.32 & 0.04 & 3 & 1.30 & 0.02 \\
\hline $4 / 3 / 86$ & 19 & $54^{\circ}$ & $54^{\circ} 01^{\prime}$ & $67^{\circ} 14^{\circ}$ & $67^{\circ}$ & $20-29$ & 23 & 190 & 0 & 0.00 & 0.00 & 1 & 0.42 & 0.01 \\
\hline $4 / 3 / 86$ & 20 & $53^{\circ}$ & $54^{\circ} 00^{\circ}$ & $67^{\circ} 16^{\circ}$ & $67^{\circ}$ & $19-22$ & 19 & 190 & 0 & 0.00 & 0.00 & 0 & 0.00 & 0.00 \\
\hline $5 / 3 / 86$ & 21 & $54^{\circ}$ & $54^{\circ} 01^{\circ}$ & $67^{\circ} 17^{\circ}$ & $67^{\circ}$ & $20-21$ & 43 & 190 & 4 & 4.30 & 0.02 & 10 & 4.20 & 0.05 \\
\hline $5 / 3 / 86$ & $22^{*}$ & $54^{\circ}$ & $54^{\circ} 03^{\circ}$ & $67^{\circ} 07^{\circ}$ & $67^{\circ}$ & $19-22$ & 21 & 190 & 12 & 10.70 & 0.06 & 7 & 3.09 & 0.04 \\
\hline $5 / 3 / 86$ & 23 & $54^{\circ}$ & $54^{\circ} 15^{\prime}$ & $66^{\circ} 46^{\circ}$ & $66^{\circ}$ & $27-21$ & 20 & 190 & 2 & 1.35 & 0.01 & 78 & 28.50 & 0.41 \\
\hline $5 / 3 / 86$ & 24 & $54^{\circ}$ & $54^{\circ} 12^{\prime}$ & $66^{\circ} 49^{\circ}$ & $66^{\circ}$ & $25-33$ & 22 & 180 & 0 & 0.00 & 0.00 & 0 & 0.00 & 0.00 \\
\hline $6 / 3 / 86$ & 25 & $54^{\circ}$ & $54^{\circ} 03^{\prime}$ & $67^{\circ} 13^{\prime}$ & $67^{\circ}$ & $16-15$ & 45 & 190 & 8 & 7.24 & 0.04 & 9 & 4.50 & 0.05 \\
\hline $6 / 3 / 86$ & 26 & 54 & $54^{\circ} 06^{\circ}$ & $66^{\circ} 44^{\prime}$ & $66^{\circ}$ & $52-28$ & 45 & 190 & 0 & 0.00 & 0.00 & 0 & 0.00 & 0.00 \\
\hline $6 / 3 / 86$ & 27 & $54^{\circ}$ & $54^{\circ} 05^{\circ}$ & $66^{\circ} 40^{\prime}$ & $66^{\circ}$ & $59-62$ & 21 & 190 & 0 & 0.00 & 0.00 & 0 & 0.00 & 0.00 \\
\hline $7 / 3 / 86$ & 28 & $54^{\circ}$ & $54^{\circ} 20^{\prime}$ & $66^{\circ} 36^{\circ}$ & $66^{\circ}$ & $22-20$ & 42 & 180 & 0 & 0.00 & 0.00 & 0 & 0.00 & 0.00 \\
\hline $7 / 3 / 86$ & 29 & $54^{\circ}$ & $54^{\circ} 18^{\prime}$ & $66^{\circ} 39^{\prime}$ & $66^{\circ}$ & $19-21$ & 44 & 190 & 0 & 0.00 & 0.00 & 0 & 0.00 & 0.00 \\
\hline $8 / 3 / 86$ & 30 & $54^{\circ}$ & $54^{\circ} 23^{\circ}$ & $66^{\circ} 32^{\circ}$ & $66^{\circ}$ & $22-22$ & 47 & 190 & 0 & 0.00 & 0.00 & 8 & 4.50 & 0.04 \\
\hline $8 / 3 / 86$ & 31 & $54^{\circ}$ & $54^{\circ} 22^{\prime}$ & $66^{\circ} 34^{\circ}$ & $66^{\circ}$ & $18-17$ & 45 & 190 & 1 & 0.00 & 0.01 & 8 & 4.20 & 0.04 \\
\hline $9 / 3 / 86$ & 32 & $54^{\circ}$ & $54^{\circ} 42^{\prime}$ & $64^{\circ} 24^{\prime}$ & $64^{\circ}$ & $46-35$ & 16 & 190 & 0 & 0.00 & 0.00 & 0 & 0.00 & 0.00 \\
\hline $9 / 3 / 86$ & 33 & $54^{\circ}$ & $54^{\circ} 43^{\prime}$ & $64^{\circ} 28^{\prime}$ & $64^{\circ}$ & $51-45$ & 17 & 190 & 0 & 0.00 & 0.00 & 0 & 0.00 & 0.00 \\
\hline $12 / 3 / 86$ & 34 & $54^{\circ}$ & $54^{\circ} 13^{\circ}$ & $60^{\circ} 20^{\circ}$ & $60^{\circ}$ & $98-95$ & 47 & 190 & 34 & 24.68 & 0.18 & 0 & 0.00 & 0.00 \\
\hline $12 / 3 / 86$ & 35 & $54^{\circ}$ & $54^{\circ} 14^{\prime}$ & $60^{\circ} 08^{\circ}$ & $60^{\circ}$ & $94-96$ & 49 & 190 & 15 & 10.31 & 0.08 & 0 & 0.00 & 0.00 \\
\hline $13 / 3 / 86$ & 36 & $54^{\circ}$ & $54^{\circ} 14^{\prime}$ & $59^{\circ} 25^{\prime}$ & $59^{\circ}$ & $86-75$ & 17 & 180 & 7 & 6.24 & 0.04 & 0 & 0.00 & 0.00 \\
\hline $13 / 3 / 86$ & $37^{*}$ & $54^{\circ}$ & $54^{\circ} 16^{\circ}$ & $59^{\circ} 29^{\circ}$ & $59^{\circ}$ & $83-87$ & 20 & 180 & 25 & 23.47 & 0.14 & 47 & 20.25 & 0.26 \\
\hline $16 / 3 / 86$ & 38 & $54^{\circ}$ & $54^{\circ} 25^{\prime}$ & $66^{\circ} 25^{\prime}$ & $66^{\circ}$ & $17-16$ & 21 & 190 & 1 & 0.70 & 0.01 & 19 & 9.30 & 0.10 \\
\hline $16 / 3 / 86$ & 39 & $54^{\circ}$ & $54^{\circ} 26^{\prime}$ & $66^{\circ} 21^{\prime}$ & $66^{\circ}$ & $18-20$ & 21 & 190 & 1 & 0.82 & 0.01 & 0 & 0.00 & 0.00 \\
\hline $16 / 3 / 86$ & 40 & $54^{\circ}$ & $54^{\circ} 25^{\circ}$ & $66^{\circ} 28^{\prime}$ & $66^{\circ}$ & $21-15$ & 22 & 190 & 1 & 0.70 & 0.01 & 14 & 7.30 & 0.07 \\
\hline $18 / 3 / 86$ & 41 & $51^{\circ}$ & $51^{\circ} 53^{\circ}$ & $68^{\circ} 41^{\prime}$ & $68^{\circ}$ & $68-48$ & 24 & 190 & 0 & 0.00 & 0.00 & 16 & 40.00 & 0.08 \\
\hline $18 / 3 / 86$ & 42 & $51^{\circ}$ & $51^{\circ} 44^{\prime}$ & $68^{\circ} 42^{\prime}$ & $68^{\circ}$ & $68-42$ & 30 & 190 & 0 & 0.00 & 0.00 & 150 & 52.00 & 0.79 \\
\hline
\end{tabular}

* Lances con mediciones de largo de caparazón. 
Tabla 6. Muestreo de largo de caparazón de centollas machos capturadas en el primer viaje del B/P $<<H o s h i n-$ Maru 2 > , en el sur del litoral Patagónico entre el $1^{\circ}$ y 18 de marzo de 1986.

Table 6. Sampling of carapace lenght of antarctic king crabs caught in the first trip of the $B / P<<H o s h i n-M a r u$ 2>>, to the south of the Patagonian littoral between the $1^{\circ}$ and 18 of March 1986.

\begin{tabular}{|c|c|c|c|c|c|}
\hline Fecha & Zona & Lance & $\begin{array}{c}\mathbf{N}^{0} \text { de } \\
\text { ejemplares }\end{array}$ & $\begin{array}{l}\text { Largo caparazón } \\
(\mathrm{mm}) \pm \mathrm{DS}\end{array}$ & Posición geográfica \\
\hline $1 / 3 / 86$ & Litoral de Tierra del Fuego & 8 & 55 & $98,1 \pm 8,5$ & $53^{\circ} 46^{`} \mathrm{~S}-67^{\circ} 35^{\prime} \mathrm{W}$ \\
\hline $2 / 3 / 86$ & $\ll$ & 9 & 93 & $108,1 \pm 8,1$ & $53^{\circ} 52^{`} \mathrm{~S}-67^{\circ} 25^{\prime} \mathrm{W}$ \\
\hline $2 / 3 / 86$ & « & 12 & 85 & $105,8 \pm 7,9$ & $53^{\circ} 54^{\prime} \mathrm{S}-67^{\circ} 22^{\prime} \mathrm{W}$ \\
\hline $3 / 3 / 86$ & $\ll$ & 13 & 63 & $110,9 \pm 9,0$ & $53^{\circ} 59^{\circ} \mathrm{S}-67^{\circ} 20^{\prime} \mathrm{W}$ \\
\hline $5 / 3 / 86$ & « & 22 & 19 & $98,9 \pm 10,1$ & $54^{\circ} 02^{\prime} \mathrm{S}-67^{\circ} 07^{\prime} \mathrm{W}$ \\
\hline $13 / 3 / 86$ & « & 37 & 25 & $104,4 \pm 8,7$ & $54^{\circ} 16^{\prime} \mathrm{S}-59^{\circ} 29^{\prime} \mathrm{W}$ \\
\hline
\end{tabular}

DS = Desviación estándar.

Tabla 7. Muestreo de largo de caparazón (Lc) de centollón macho capturado en el primer viaje del B/P $<<H o s h i n$ Maru 2 > en el sur del litoral Patágonico $\left(1^{\circ}\right.$ al 18 de marzo 1986)

Table 7. Sampling of males'carapace lenght (Lc) of $<<$ centollon $>>$ caught in the first trip of the B/P $<<$ Hoshin Maru2 $>$, to the south of the Patagonian littoral between the $\left(1^{\circ}\right.$ and 18 of March 1986$)$.

\begin{tabular}{|c|c|c|c|c|c|}
\hline Fecha & Zona & Lance & $\begin{array}{c}\mathrm{N}^{\circ} \mathrm{de} \\
\text { ejemplares }\end{array}$ & $\begin{array}{l}\text { Largo caparazón } \\
\quad(\mathrm{mm}) \pm \mathrm{DS}\end{array}$ & Posición geográfica \\
\hline $1 / 3 / 86$ & Litoral de Tierra de Fuego & 8 & 5 & $85,2 \pm 8,2$ & $53^{\circ} 46^{\prime} \mathrm{S}-67^{\circ} 35^{\prime} \mathrm{W}$ \\
\hline $2 / 3 / 86$ & « & 9 & 62 & $92,0 \pm 5,6$ & $53^{\circ} 52^{\prime} \mathrm{S}-67^{\circ} 25^{\prime} \mathrm{W}$ \\
\hline $3 / 3 / 86$ & $\ll$ & 12 & 101 & $86,4 \pm 6,9$ & $53^{\circ} 54^{\prime} \mathrm{S}-67^{\circ} 22^{\prime} \mathrm{W}$ \\
\hline $13 / 3 / 86$ & $\ll$ & 37 & 35 & $90,8 \pm 8,1$ & $54^{\circ} 16^{\prime} \mathrm{S}-59^{\circ} 29^{\prime} \mathrm{W}$ \\
\hline
\end{tabular}

DS = Desviación estándar.

Tabla 8. Muestreo de largo de caparazón de centollas capturadas en el $5^{\circ}$ y $6^{\circ}$ viaje del $\mathrm{B} / \mathrm{P}<<$ Hoshin Maru 2>> en el sur del litoral Patagónico (28 de septiembre al 15 de octubre de 1986).

Table 8. Sampling of caparace lenght of antarctic king crabs caught in the fifth and sixth trip of the $B / P$ $<<$ Hoshin Maru 2>>, to the south of Patagonian littoral (September 28 - October 15, 1986).

\begin{tabular}{|c|c|c|c|c|c|}
\hline Area explorada & $\mathbf{N}^{\circ}$ & $\begin{array}{c}\text { Sexo } \\
\text { de ejemplares }\end{array}$ & $\begin{array}{l}\text { Largo caparazón } \\
\quad(\mathrm{mm}) \pm \mathrm{DS}\end{array}$ & $\begin{array}{l}\text { Peso medio } \\
\text { (g) } \pm \text { DS }\end{array}$ & $\begin{array}{l}\text { Posición } \\
\text { geográfica }\end{array}$ \\
\hline $\begin{array}{l}\text { Bahía Grande } \\
\text { (frente a R. Gallegos) }\end{array}$ & 39 & machos & $116,3 \pm 9,34$ & $1145,0 \pm 222$ & SIN POSICION \\
\hline Frente a Isla Grande & & & & & \\
\hline $\begin{array}{l}\text { Tierra del Fuego } \\
\text { Frente a Isla Grande }\end{array}$ & 21 & machos & $109,5 \pm 9,3$ & $1008,0 \pm 162$ & $53^{\circ} 37^{\prime} \mathrm{S}-64^{\circ} 45^{\prime} \mathrm{W}$ \\
\hline $\begin{array}{l}\text { Tierra del Fuego } \\
\text { Frente a Isla Grande }\end{array}$ & 50 & machos & $103,5 \pm 12,6$ & $828,2 \pm 257$ & $53^{\circ} 51^{`} \mathrm{~S}-67^{\circ} 23^{`} \mathrm{~W}$ \\
\hline Tierra del Fuego & 40 & hembras & $72,5 \pm 6,8$ & $330,7 \pm 74$ & $53^{\circ} 50^{\circ} \mathrm{S}-67^{\circ} 19^{\circ} \mathrm{W}$ \\
\hline
\end{tabular}

DS = Desviación estándar. 
ambos sexos, comportamiento frecuente en estos crustáceos, como se ha comprobado por las investigaciones realizadas en el Canal Beagle (Boschi et al., 1984; Vinuesa, 1984). Al final de la 6a etapa del viaje, en octubre, frente a Tierra del Fuego, se capturaron ejemplares de ambos sexos. Precisamente esa es la época en que se inicia el ciclo reproductivo, la muda y acoplamiento de los adultos en mar abierto por lo cual se agrupan las centollas de ambos sexos (Vinuesa, 1985) (Tabla 8).

Los resultados de este viaje ponen en evidencia que en las áreas costeras de Santa Cruz y Tierra del Fuego, existen en algunos meses del año (primavera y otoño) ciertas concentraciones de centolla y centollón, si bien los rendimientos en general han sido bajos. Por otra parte es interesante destacar que el tamaño medio de la centolla del litoral patagónico, medidas en 1960 se aproximan a las de esta última campaña de 1986, luego de los 25 años transcurridos entre una y otra, aunque las artes de capturas fueron diferentes.

Será interesante en un futuro realizar comparaciones de tallas y distribución de sexos en varias épocas del año, entre las centollas capturadas en las diferentes localidades del litoral patagónico, particularmente con las que actualmente se extraen del golfo San Jorge.

\section{Camarón argentino}

El camarón (Artemesia longinaris) es un peneido costero, con distribución limitada entre el sur de Brasil, desde la latitud $22^{\circ} \mathrm{S}$ en proximidades de Rio de Janeiro, hasta el litoral de Chubut, latitud $43^{\circ} \mathrm{S}$ en la República Argentina. Las capturas fluctúan anualmente, aunque en menor proporción que las del langostino. Se realizaron estudios biológicos y biológicos pesqueros de esta especie en la región frente a la ciudad de Mar del Plata a partir de 1965 (Boschi, 1969 y datos inéditos de 199496; Boschi y Scelzo 1977 y Petriella y Bridi, 1992), los que brindaron importantes conocimientos sobre la estructura de los efectivos existentes en la zona de estudio, características de los desplazamientos, crecimiento, distribución de larvas, etc. El ciclo reproductivo fue considerado por Christiansen y Scelzo (1971). También Carriquiriborde (1984) realizó estudios poblacionales de los stocks del litoral de la Provincia de Chubut.

En cuanto a la talla de esta especie, se observa que los de mayor tamaño se hallan en el litoral de la Argentina, comparándolos con los de Uru- guay y el Sur de Brasil. Tanto en las costas de Chubut (Bahía Engaño) como en las de Mar del Plata se hallan los ejemplares que alcanzan las mayores longitudes.

En general, se observa un gradación en las tallas del camarón en toda el área de distribución, desde el sur de Brasil con tamaños medios más pequeños, hasta el litoral patagónico con los de mayor tamaño. Nascimiento (1980) halló que las tallas máximas correspondían a machos de $22,5 \mathrm{~mm}$ de Lc y hembras de 26,5 mm de Lc y Ruffino (1991) y Ruffino y Castello (1992), observaron que las tallas mayores de machos fueron de $18,5 \mathrm{~mm}$ Lc y las de hembras de $22,5 \mathrm{~mm}$, ambos muestreos realizados en aguas del Estado de Rio Grande do Sul, Brasil. En las costas de Mar del Plata, los tamaños mayores para macho han sido de $24,0 \mathrm{~mm}$ y en hembras de 29,0 $\mathrm{mm}$ de Lc en distintos períodos del muestreo. En el litoral de la provincia de Chubut, en Playa Unión, se ha verificado que las tallas extremas tanto de machos como de hembras pueden llegar a 27,0 y $37,0 \mathrm{~mm}$ de $\mathrm{Lc}$ respectivamente (Boschi y Mistakidis, 1966).

Las mayores capturas de este peneido se obtienen en Brasil. En la región Sudeste-Sur de ese país, que comprende los Estados de Espiritu Santo, Rio de Janeiro, São Paulo, Paraná, Santa Catarina y Rio Grande do Sul, las capturas de camarón, que en Brasil lo llaman "camarao barba ruca" aumentaron considerablemente desde 1978 y hasta 1991 (último dato disponible). La media de los desembarques correspondiente a este período de 12 años es de 2.190 tm/año (Tabla 10) (F. D’Incao, com. pers.)

Esta especie se pesca en aguas costeras de los itorales de las provincias de Buenos Aires y Chubut en la Argentina, con desembarques medios en los últimos 16 años de $204 \mathrm{tm}$ (Fig. 1 y Tablas 1 y 9).

Tabla 9. Desembarques totales de camarón por puerto, entre 1990 y 1994 (en tm).

Table 9. Total shrimp landings by port from 1990 through 1994 (in mt).

\begin{tabular}{|lccccr|}
\hline Puerto & $\mathbf{1 9 9 0}$ & $\mathbf{1 9 9 1}$ & $\begin{array}{c}\text { Año } \\
\mathbf{1 9 9 2}\end{array}$ & $\mathbf{1 9 9 3}$ & $\mathbf{1 9 9 4}$ \\
\hline Mar del Plata & 52,0 & 37,574 & 68,187 & 73 & 73,8 \\
Quequén & 0,162 & - & 0,001 & - & - \\
Bahía Blanca & 139,0 & 108,876 & 271,87 & 109 & 131,3 \\
Pto. Madryn & - & 0,805 & 0,18 & - & 6,8 \\
Rawson & - & 1,31 & 39,62 & 3 & - \\
Caleta Córdoba & - & - & 0,120 & - & - \\
B. Camarones & 0,003 & 0,020 & - & - & - \\
\hline
\end{tabular}


Tabla 10. Desembarques en la región sudeste de Brasil de camarón y langostino, entre 1979 y 1989 (en tm).

Table 10. Shrimps and langostinos' landings in the southeast region of Brasil for the period 1979-1989 (in mt).

\begin{tabular}{|rrc|}
\hline Año & Camarón & Langostino \\
\hline 1978 & 901 & 190 \\
1979 & 495 & 520 \\
1980 & 2050 & 583 \\
1981 & 1791 & 422 \\
1982 & 2219 & 1086 \\
1983 & 2219 & 1164 \\
1984 & 2883 & 1504 \\
1985 & 2017 & 842 \\
1986 & 1115 & 502 \\
1987 & 2012 & 1591 \\
1988 & 3734 & 4112 \\
1989 & 1185 & 1889 \\
1990 & 2463 & 1202 \\
1991 & 2004 & 543 \\
\hline
\end{tabular}

Este camarón tienen menos interés que el langostino, especialmente por la menor talla que no sobrepasa normalmente los $135 \mathrm{~mm}$ de Lt. en la zona de Mar del Plata, pero el grueso de la captura corresponde a ejemplares más pequeños. Por otra parte, la abundancia del camarón no ha experimentado aumentos espectaculares como ocurre con el langostino, manteniéndose en cifras que oscilaron entre 48 a 430 tm en los últimos catorce años (Tabla 1). En la provincia de Buenos Aires aproximadamentre el 50\% del camarón se destina a carnada para la pesca deportiva, que se práctica intensamente en playas y escolleras durante todo el año. En este caso el camarón se vende fresco, sin cocinar, pero muerto.

En cuanto a las capturas de la flota pesquera y los muestreos de desembarques del camarón Artemesia longinaris realizados en el Puerto de Mar del Plata, en el transcurso de algunos meses de primavera y verano de 1994, 1995 y 1996 el recurso se ha presentado en abundancia, evidenciando excelentes condiciones en cuanto a la estructura de la población en estudio (Boschi, MS).

\section{Langostino}

El langostino (Pleoticus muelleri) es la principal especie de peneido del litoral de la Argentina. Su distribución comprende aguas costeras de las provincias de Buenos Aires, Chubut y Santa Cruz (Fig. 1). Hacia el norte, sobrepasa los límites de Argentina y llega hasta Rio de Janeiro, Brasil. Las capturas en toda esta área han variado acentuadamente en los distintos años. Lo más espectacular ha sido, sin duda, los importantes incrementos de las capturas en el litoral patagónico a partir de 1981 (Fig. 2 y Tabla 1). También en el Sudeste de Brasil, desde 1979 comenzaron los registros de desembarques de langostino, que en algunos años llegaron a cifras considerables, con un máximo en 1988 de 4.112 tm, descendiendo los desembarques en los últimos años con un registro en 1991 de 543 tm (F. D'Incao, 1993, com. pers.) (Fig. 2 y Tabla 10).

Las pesquerías del langostino establecidas en la Argentina tienen cierta tradición, porque desde hace más de sesenta años existen registros de desembarques en algunos puertos. Las regiones de capturas actuales de esta especie están ubicadas en el litoral de la provincia de Buenos Aires, en las áreas de Mar del Plata hasta Mar Chiquita. Otra en la amplia región de la Bahía Blanca y El Rincón y hacia el sur el langostino se encuentra en las aguas costera de Chubut y el golfo San Jorge que abarca parte de las costas de esa provincia y Santa Cruz. (Fig. 1). Cada una de estas tres áreas de pesca alberga poblaciones de langostinos independientes entre sí.

La pesquería en el litoral de la Provincia de Buenos Aires. En las mencionadas áreas de pesca de la provincia de Buenos Aires, frente a Mar del Plata y con puerto de desembarque es esa ciudad, la captura del langostino se realiza con embarcaciones pequeñas, entre 7 y $20 \mathrm{~m}$ de eslora, integrantes de la denominada flota de "rada o ría", pintadas de color amarillo. Realizan viajes diarios con la entrega del producto fresco, hervido a bordo o crudo, sin ningún tipo de refrigeración. Las embarcaciones no emplean equipos hidroacústicos para la detección de las concentraciones de langostino y la pesca se basa sólo en la pericia del patrón de la lancha.

Los barcos de mayor eslora, entre 18 y $22 \mathrm{~m}$, que se dedican temporariamente a esta pesca, tienen guinche para recoger el aparejo. En cambio en las lanchas, esa maniobra se realiza mediante el empleo de una polea accionada por el motor, donde se enrosca una cuerda que iza la red. En aguas costeras del litoral de Chubut, Bahía Engaño y áreas adyacentes, también se pesca langostino con barquitos de la flota amarilla.

En los meses de verano, en días de buena cosecha una lancha o barquito costero puede traer a puerto entre cuatro a ocho cajones de langostino de buena talla (30 kg/cajón). Cuando la pesca es muy abundante los pescadores establecen un número máximo de cajones por lancha para mantener el pre- 
cio en el mercado local. Esta es una pesca semiartesanal que lentamente ha ido progresando con la

incorporación de radio en las embarcaciones y casillaje para albergar la tripulación. En algunos casos tienen ecosondas para conocer la profundidad y tipo de fondo de la región de pesca y han sustituido el raño (beam trawl) como arte de pesca por pequeñas redes de arrastre con puertas o portones.

La descripción de los procedimientos y características de la pesca del langostino en la región del Mar de Plata fueron tratados por Angelescu y Boschi (1959). Los métodos de captura, las fluctuaciones de su abundancia desembarques en la región de la Bahía Blanca, han sido discutidos por Wyngaard y Bertuche (1982).

Las capturas en las regiones de Bahía Blanca y Mar de Plata, han variado permanentemente. En ciertos años se observa algún aumento de la abundancia del recurso, pero en general ha tenido poco significado en el total de desembarques de la especie (Tabla 11). En los últimos 5 años se han mantenido los volúmenes medios de capturas en Mar del Plata en unas 204 tm y en Bahía Blanca, para el mismo período en $219 \mathrm{tm}$. Parte de las capturas de langostino en la provincia de Buenos Aires se destinan a consumo interno.

La pesquería en el litoral patagónico. Los fondos actuales de pesca más importantes de lan-

Tabla 11. Desembarques totales de langostino por puerto, entre 1990 y 1994 (en tm).

Tabla 11. Total langostino landings by port from 1990 through 1994 (in mt).

\begin{tabular}{|lrrrrr|}
\hline Puerto & \multicolumn{6}{c|}{ Año } \\
& $\mathbf{1 9 9 2}$ & $\mathbf{1 9 9 0}$ & $\mathbf{1 9 9 1}$ & $\mathbf{1 9 9 3}$ & $\mathbf{1 9 9 4}$ \\
\hline Mar del Plata & 282 & 208 & 177 & 186 & 168 \\
Quequen & 9 & 7 & - & - & - \\
Bahía Blanca & 200 & 234 & 420 & 106 & 43 \\
Pto. Madryn & 3.746 & 2.284 & 6.515 & 4.945 & 5.818 \\
Pto. Deseado & 4.102 & 4.099 & 14.872 & 11.256 & 8.710 \\
C. Rivadavia & 673 & 89 & 754 & 766 & 894 \\
Rawson & 34 & 153 & 312 & 121 & 120 \\
Caleta Córdoba & 1 & - & 1 & - & - \\
Bahía Camarones & 58 & 8 & 239 & - & - \\
Buenos Aires & 350 & 93 & - & - & - \\
San Clemente & 2 & - & - & - & - \\
San Julián & 362 & 532 & 1013 & - & - \\
\hline
\end{tabular}

gostino se hallan en el litoral de Chubut y en el golfo San Jorge (Fig. 3). A partir de 1981 las capturas aumentaron en tal magnitud, que se intensificaron los estudios de ese recurso. Desde 1982 hasta el presente, se llevaron a cabo en esa región más de 30 campañas de investigación pesquera con las naves del INIDEP y la participación de un importante grupo de investigadores de distintas disciplinas. Todas esas tareas de conjunto han permitido profundizar el conocimiento sobre los stocks del langostino patagónico.

Al comienzo de esta etapa de abundancia de langostino, existía una gran incertidumbre sobre la potencialidad del recurso y como se adecuaría el ordenamiento pesquero para asegurar un rendimiento sostenido del mismo. Distintas agrupaciones de industriales, armadores y pescadores, se acercaron a INIDEP para pedir asesoramiento sobre ese nuevo recurso, que demandaba mayor cantidad de barcos, con mejores equipos, redes de pesca apropiadas para una eficiente extracción, capitanes idóneos para esa pesca y plantas en tierra que permitieran un procesamiento adecuado al valor del producto, con el fin de conquistar mercados internacionales. A raíz de todo ello y en razón del excelente diálogo mantenido con empresarios interesados en ese recurso, en 1984 se concretó un convenio con la Cámara de Armadores de Pesqueros Congeladores (CAPECA), de Buenos Aires. Ello permitió disponer de fondos complementarios para alistar varias campañas especiales de investigación con los BIP del INIDEP, durante 1984 y 1985. Posteriormente, otras empresas de Mar del Plata, se sumaron en la financiación de campañas. Este tipo de colaboración se menciona como un ejemplo de entendimiento y buena voluntad entre un Instituto Técnico del Estado y la actividad privada.

Desde 1980 la abundancia del langostino patagónico se ha mantenido, con oscilaciones que van entre 2,142 tm en 1987 hasta el desembarque máximo de 24,397 tm en 1992. Las estadísticas oficiales indicaron para $1994,15,826 \mathrm{tm}$. Las pocas capturas de 1987 coincidieron con una pesca de juveniles y subadultos intensiva transgrediendo el área de veda de Mazarredo (Fig. 3) donde se ubica el mayor fondo de crianza. La escasez de langostino durante 1995 se atribuyó a las mismas cusas (Revista Redes, 1995).

En la región frente al Bajo Mazarredo, como dijo anteriormente, se halla la mayor concentración de langostino juveniles y subadultos durante casi todo el año, con una menor fracción de adultos. Una 
pequeña cantidad de hembras impregnadas fueron halladas en las campañas H-O1/85 de 1985 y en OB-O1/90, en 1991 y en marzo en la campaña OB$\mathrm{O} 2 / 85$. En otras campañas se encontraron en enero (INIDEP EH-01/95, EH/02/95), una cantidad mayor de hembras impregnadas en relación con la habitual baja proporción. Además en Mazarredo prácticamente no se han hallado, hasta el presente, huevos ni larvas de langostino, lo cual hace pensar que a esa región ingresan postlarvas y juveniles de otras áreas.

Se ha postulado, en varios trabajos e informes, la mezcla de los distintos efectivos de langostino del litoral patagónico, con variables intensidad y épocas (Bertuche et al., 1985a, 1987; Boschi, 1989). También se ha mencionado que existen agrupaciones menores que tienen movimientos reducidos y aislados (Boschi, 1989).

Los caladeros de este crustáceo se sitúan preferentemente en las costas de Rawson, Bahía Camarones y en el golfo San Jorge. La presencia de concentraciones de interés pesquero no es permanente ni homogénea durante el transcurso del año en las mencionadas áreas. Tradicionalmente los pescadores conocen que en el norte de San Jorge y litoral de Chubut, en el verano se halla el langostino de mayor talla, vulnerable a la red de pesca. En el norte del golfo se encuentra principalmente en reproducción en diciembre, frente a las islas Pan de Azucar, Tova y Tovita. En enero, febrero y a veces en marzo, frente a Bahía Camarones y en la Bahía Engaño e inmediaciones (Provincia de Chubut), donde también se han hallado concentraciones importantes de los distintos estadíos larvales, postlarvales y juveniles, especialmente entre diciembre y abril. Se han detectado asimismo huevos y larvas de langostino frente a Península Valdés, pero las capturas comerciales habituales registradas por las estadísticas de pesca figuran por debajo de la latitud $43^{\circ} \mathrm{S}$.

Queda por demostrar en qué medida estas concentraciones, originadas en las zonas de Rawson, Camarones y norte del golfo pueden cumplir un ciclo independiente de las del sur del golfo, particularmente de los grandes fondos de crianza de Mazarredo. Si es así, cual es el aporte de langostino de esas zonas en la captura de cada temporada de pesca y si existe algún tipo de sincronismo entre las mismas. Es necesario conocer además, si esas producciones pueden sumarse o compensarse. Entonces, si las áreas mencionadas tienen producciones independientes, no se podría explicar la escasez de langostino en 1995, por haber sido afectada sola- mente la zona sur por la pesca en sector vedado. Esto parece ser una evidencia más para sostener que, desde el punto de vista biológico, el langostino del litoral patagónico debe ser considerado básicamente como una unidad, con sólo pequeñas fracciones independientes.

La vinculación entre langostinos originados en distintos sectores de su amplia área de reproducción es variable en amplitud e intensidad y no ocurre en el transcurso de todo el año. Las observaciones oceanográficas realizadas en el golfo San Jorge y el aporte de estudios sobre otros organismos (Hart, 1946; Balech, 1971, 1986; Boschi, 1989; Orozco y Carreto 1989; Severov, 1990), así como estudios sobre la deriva de sedimentos litorales (Codignotto et al., 1990) ponen en evidencia la existencia de lenguas de aguas de dirección S-SW en los meses de primavera y verano que serían responsables del transporte de las postlarvas y juveniles, en esas épocas del año, hacia el sur del golfo. Esto se encuadra en el esquema de que la fase larval o postlarval de una especie puede ser retenida dentro de una masa de agua y transportada a áreas muy distantes, como ocurre, por ejemplo con la larva filosoma de las langostas Panulirus de Australia o América del norte (Sinclair, 1988). Siguiendo este criterio las variaciones en la abundancia dependerían de las características y movimiento de la masa de agua, más que de las interrelaciones con otros organismos.

Se ha observado, además, una gradación de tallas de sur a norte, de acuerdo con los muestreos realizados en numerosas campañas de investigación con los BIP del INIDEP (Bertuche et al., 1985a; Boschi, 1989). En el sur los tamaños medios son más pequeños que los del centro y norte, así como la proporción de hembras maduras e impregnadas y los machos maduros aumentan hacia la zona norte de su distribución (Fig. 4). En aguas afuera del centro del golfo, se suele obtener muy buenas capturas de langostino grande, de varias toneladas por lance, como ocurrió en 1992. De esa zona provino gran parte del desembarque de ese año, conjuntamente con los de la zona sur (Mazarredo), con más de 14.000 tm. En Bahía Camarones y en la zona frente a Rawson (Chubut), también se obtuvieron buenas capturas con cerca de 7.000 tm de un producto de las primeras tallas comerciales (entre $15 \mathrm{y}$ 30 piezas por $\mathrm{kg}$ ).

Lo que surge como algo primordial, por otra parte, es que no se debe descuidar de relacionar las condiciones ambientales de las áreas de estudio con los desplazamientos y cambios del langostino en los 

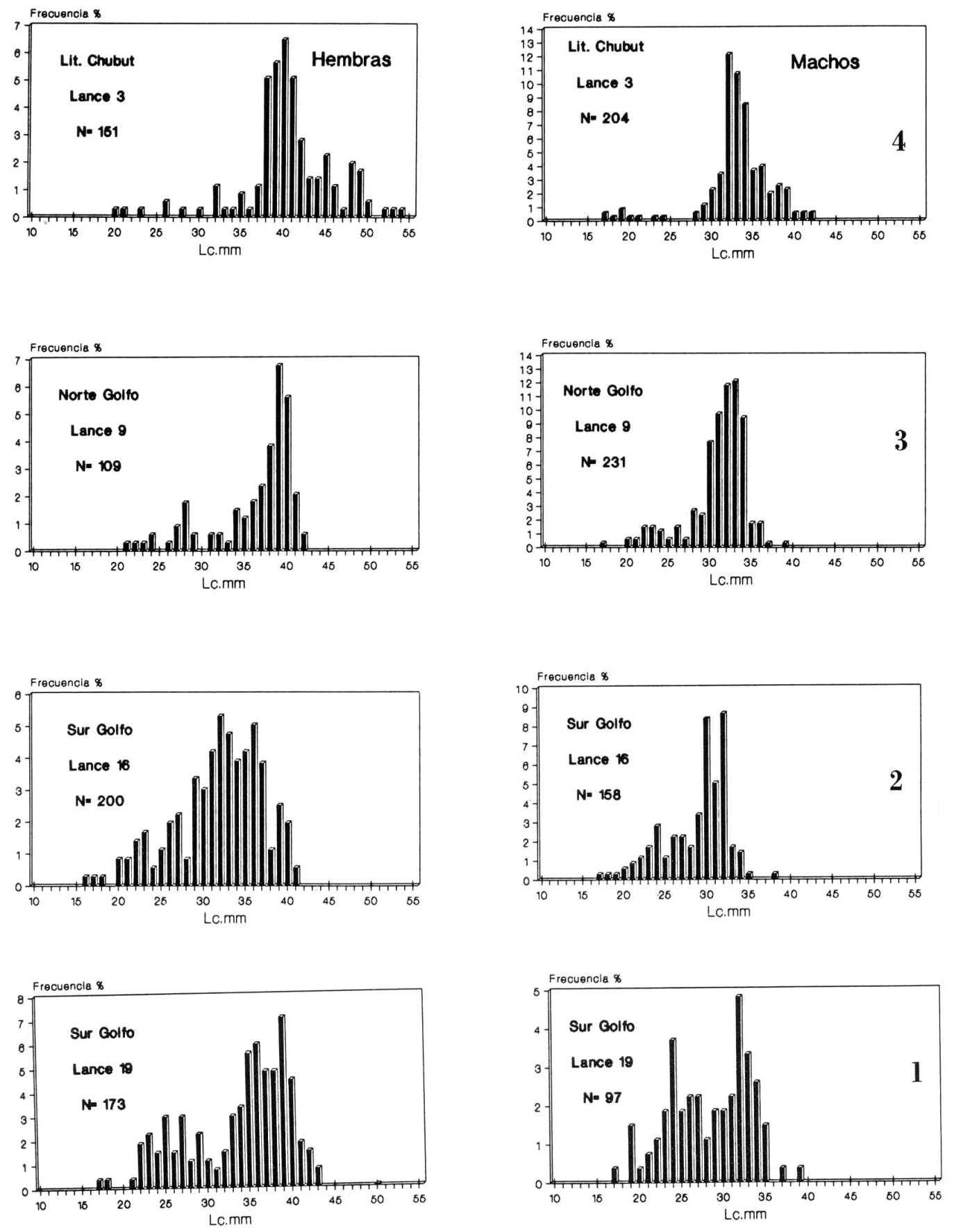

Figura 4. Histogramas de distribución de tallas del langostino (Pleoticus muelleri) en lances de pesca con barco de investigación en el litoral patagónico. 1 y 2: zona sur (Mazarredo), 2: norte del golfo San Jorge y 3: litoral de Chubut.

Figure 4. Histograms of size distribution of Argentine red shrimp (Pleoticus muelleri) obtained from catches carried out with research vessels off Patagonian coast. 1 and 2: southern zone (Mazarredo), 2: northern Gulf of San Jorge; 3: coastal zone of Chubut. 
distintos períodos de vida. Las temperaturas bajas, por ejemplo, inferiores a $12-13^{\circ} \mathrm{C}$, propias de la zona de Mazarredo, puede afectar el período normal de desarrollo embrionario de los huevos y reducir a un mínimo la eclosión de los mismos, como se ha comprobado en experiencias de cultivo realizadas con este peneido (Sarlo, 1995).

El empleo de varios tipos de rastras bentónicas, especialmente diseñadas para la captura de postlarvas avanzadas y juveniles, iniciada en la campaña OB-08/89, ha arrojado interesantes observaciones sobre la distribución y abundancia de prerreclutas en el área de estudio, tarea que se sigue realizando y está aportando una valiosa información sobre la distribución de la especie en esas etapas del ciclo vital. Un tipo similar de red epibentónica (rastra) fue utilizada también con éxito por Carriquiriborde (1984) para la captura de juveniles de Artemesia longinaris en Bahía Engaño, Chubut.

La flota se compone de factorías, congeladores y fresqueros, sumándose a estos en los últimos años los congelados tangoneros, del tipo utilizado en la pesca de camarones en áreas tropicales, pero de mayor eslora (35-45 m). En total cerca de 100 barcos pueden dedicarse a la pesca de este crustáceo en algunas épocas del año. La incorporación de tangoneros en la explotación de langostino en el litoral de Argentina ha sido una decisión importante, en razón de la buena operatividad de este tipo de congelador y con alta eficiencia de pesca, lo que puede asegurar excelentes rendimientos. Pero debido a las característica del Atlántico sur, frecuentemente con vientos intensos, fue necesario aumentar la eslora de estos barcos, para asegurar la actividad de los mismos en días de adversas condiciones meteorológicas.

Como se mencionó anteriormente el recurso langostino se ha mantenido, permitiendo una captura sostenida conformado por varias cohortes en el año, pero con las típicas oscilaciones propias de una especie de vida corta (Boschi, 1989). Las capturas en las mejores épocas del año, entre diciembre y abril, pueden ser muy elevadas y no es extraño que un barco congelador, luego de una marea de 45 días entre a puerto con 200 o 300 toneladas de este crustáceo. En algunos años, las buenas capturas continúan en la estación fría, como ha ocurrido en 1993 que, salvo en junio, en todos los meses se lograron buenos rendimientos.

En muchas ocasiones el recurso se presenta compacto, fácil de ubicar y capturar con la red de arrastre. En las Figs. 5 y 6 se observa el registro ecoico del langostino en Mazarredo, donde se detectaron importantes concentraciones de este crustáceo y cardúmenes de merluza sobre los mismos. Es interesante destacar que en la composición del alimento de la merluza, tiene escasa incidencia el langostino.

Esta especie tiene una ordenación pesquera propia y está regida por resoluciones de la Secretaría de Agricultura, Pesca y Alimentación del Ministerio de Economía de la Nación, pero también las provincias de Chubut y Santa Cruz, que comparten la extracción del recurso, han establecido sus propias reglamentaciones que abarcan las aguas internas del golfo San Jorge, declarando a éste como una unidad biológica y económica. Particularmente de esta última provincia depende la imposición de los límites y cambios de la veda en el sur del golfo (zona de Mazarredo).

El mantenimiento de la veda en el sur del golfo San Jorge (Fig. 3), que incluye la mayor área de reclutamiento de este crustáceo en el litoral patagónico, ha demostrado ser una medida adecuada, en razón de que se protegen los fondos de sedimentos blandos de esa zona, apropiados para el langostino juvenil y se evita la mortalidad de los mismos que allí predominan. Por otra parte y en alguna medida, se protege de igual manera a la merluza juvenil que también abunda en la zona sur del golfo, como se ha comprobado en numerosas campañas.

El ingreso a la zona de veda de barcos de investigación y la determinación de las biomasas de langostino juvenil allí existentes, en dos o tres épocas precisas del año, permiten disponer de estimaciones sobre los efectivos capturables en los siguientes meses. El crecimiento rápido del langostino en primavera-verano, acompañando los desplazamientos hacia el norte y fuera de la zona de veda, permiten estimar las capturas en los meses siguientes tal como el INIDEP lo ha hecho en repetidas oportunidades (Boschi, 1989).

El langostino normalmente se pesca en horas diurnas, con redes de arrastre de fondo, pero durante la noche puede ascender alejándose del fondo entre 15 o $20 \mathrm{~m}$ lo que posibilita el uso de redes de gran abertura vertical o redes de arrastre de media agua. Algunos capitanes aseguran que el langostino se puede acercar a sólo 10 o $15 \mathrm{~m}$ de la superficie, siempre en horas nocturnas, en fondos de pesca de 


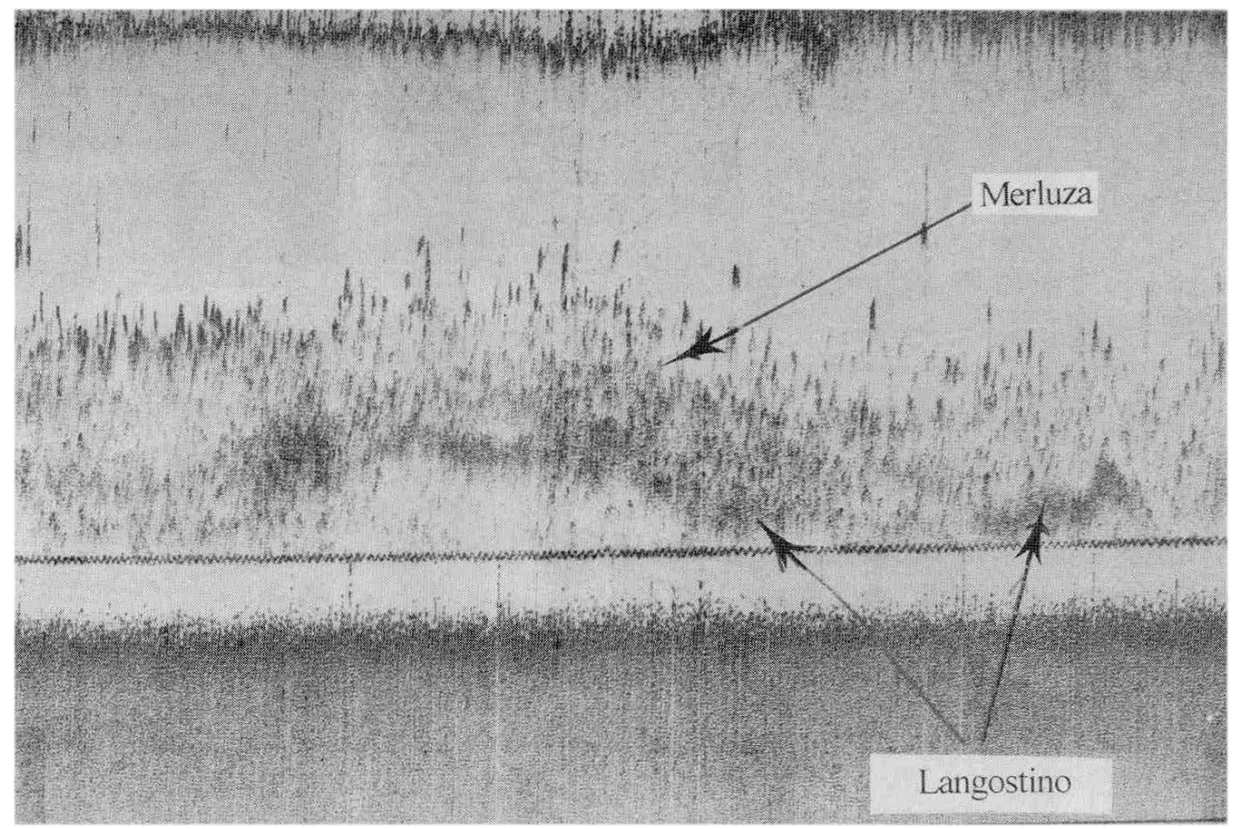

Figura 5. Registro ecoico de langostino (Pleoticus muelleri) en el golfo San Jorge, zona de Mazarredo $\left(46^{\circ} 45^{\prime}\right.$ S$66^{\circ} 38^{\prime}(\mathrm{W})$, a $65 \mathrm{~m}$ de profundidad.

Figure 5. Echo sounder record of Argentine red shrimp (Pleoticus muelleri), in the area of Mazarredo $\left(46^{\circ} 45^{\prime} \mathrm{S}-\right.$ $6^{\circ} 38^{\prime}$ W), Gulf of San Jorge, in 65 m water depth.

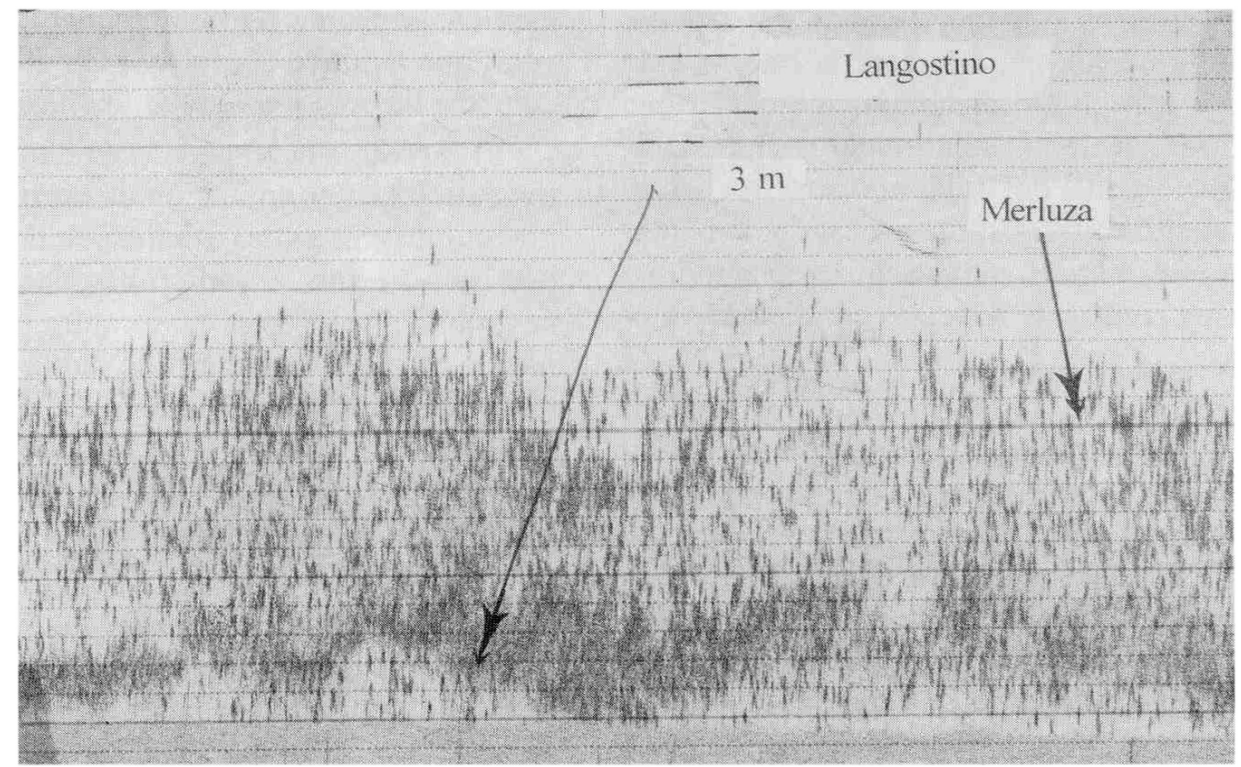

Figura 6. Registro ecoico de langostino (Pleoticus muelleri) en el golfo San Jorge, levantado del fondo.

Figure 6. Echo sounder record of Argentine red shrimp (Pleoticus muelleri) in the Gulf of San Jorge, raised from the bottom. 
50 y 70 m. Además, las capturas de postlarvas con redes de plancton a distintas profundidades y la pesca de adultos con redes de arrastre de media agua, ponen en evidencia la capacidad de esta especie de mantenerse en el pelagial nerítico, aunque el hábitat específico de los adultos, está sobre o cerca del fondo. De ahí que se empleen para la pesca comercial, redes que tienen una abertura vertical de 1,5 a 4,5 $\mathrm{m}$.

Este peneido tiene un comportamiento que determina la necesidad de enterrarse en el sustrato en horas diurnas en áreas donde existe una intensa penetración de la luz, corroborado en varias experiencias realizadas en cautividad. En las zonas de pesca esto queda atenuado por la profundidad y turbiedad del agua.

Un problema grave en la pesquería del langostino, es el descarte de la pesca acompañante, con la que se puede perder gran cantidad de pescado, especialmente merluza que abunda en todo el golfo, siendo a veces juvenil. También al comienzo de la pesquería del langostino en 1982, en la zona sur de Mazarredo, antes de la veda, existieron grandes descartes de langostino juvenil que no se aprovechaba por tener talla pequeña. El descarte de la fauna acompañante en barcos camaroneros es en realidad un problema de orden mundial, perdiéndose anualmente en países tropicales entre tres a cinco millones de tm de pescado por esas causas (Labon, 1983).

Durante las campañas de investigación pesquera del INIDEP, entre 1982 y 1989, se ha puesto de manifiesto una relación inversa entre las capturas de langostino y de merluza. Al analizar los resultados de 417 lances de pesca, agrupados por distintas zonas (Rawson, Camarones, norte, centro y sur del golfo San Jorge. Fig. 3), y de tres épocas del año (verano-otoño, invierno y primavera), se obtuvieron 12 pares de valores promedios que están representados por la curva de la Fig. 7. En algunos lances aislados, no obstante, se ha pescado volúmenes equivalentes de las dos especies y también hubo capturas de langostino con muy pocos peces.

Se ha diseñado un dispositivo destinado a lograr una mayor selectividad en la pesca del langostino, construido por tecnólogos del INIDEP (Ing. Ercoli y colaboradores). Consiste en instalar entre la antebolsa y la bolsa de la red, una o dos grillas metálicas, que permiten el escape de los peces. Esto reduce la captura de merluza demostrando una alta eficiencia, por lo cual existen disposiciones que obli-

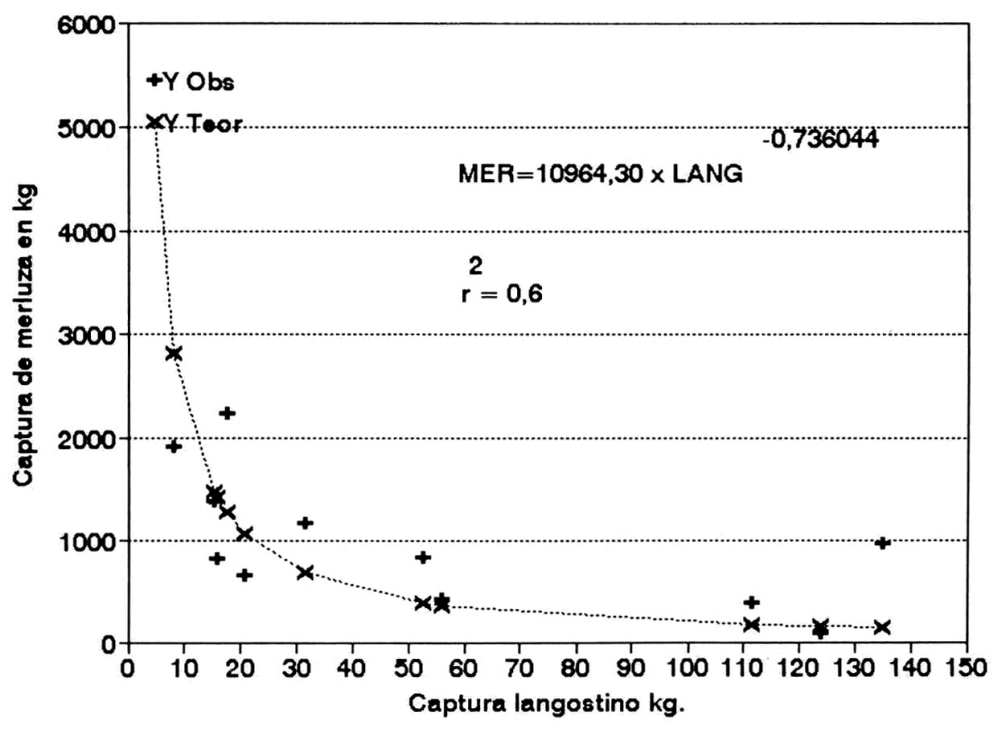

Figura 7. Regresión potencial negativa de 417 lances de pesca exploratorios con red de arrastre de fondo, realizados en el litoral patagónico (1982 y 1989), donde se observa una relación inversa entre la abundancia de merluza (Merluccius hubbsi) y de langostino (Pleoticus muelleri).

Figure 7. Negative potential regression for 417 catches from an exploratory bottom trawl fishery carried out along the coast of Patagonia (1982- 1989) indicating an inverse relationship between the abundance of hake (Merluccius hubbsi) and Argentine red shrimp (Pleoticus muelleri) 
gan su uso en la pesca de langostino en el litoral patagónico. Los estudios sobre este tipo de dispositivos continuan con el fin de perfeccionarlo (Revista Redes, 1995).

\section{Cangrejo nadador}

Es una especie de cangrejo Portunidae (Ovalipes trimaculatus) de amplia distribución que incluye áreas del Océano Pacífico Sudeste, Atlántico Sudoeste, Africa del Sur y Océano Indico. En el litoral de Argentina se presenta en toda la región costera de la provincia de Buenos Aires hasta el litoral de Chubut. Las capturas son poco significativas, pero existe continuidad en las mismas. El promedio de desembarque anual en los últimos 14 años ha sido de sólo 10,5 tm (Tabla 1).

Este cangrejo se extrae con pequeñas embarcaciones costeras con redes de arrastre de fondo en zonas de sustrato blando arenoso, donde se pesca langostino, camarón y peces de fondo, se lo considera como fauna acompañante. También se captura con mediomundo (atarraya) con carnada.

Debido a que los machos tienen una talla entre 35 y $80 \mathrm{~mm}$ de Lc mayor a la de las hembras, son más apreciados que éstas por tener los quelípedos más robustos. El tamaño de las hembras oscila entre 15 y $70 \mathrm{~mm}$ de Lc, de acuerdo con los resultados de Fenucci y Boschi (1975). En ese trabajo se empleó una embarcación costera para la captura de los cangrejos mediante el uso de mediomundo con carnada. La escasa producción de esta especie se destina al mercado interno y suele venderse hervido.

\section{AGRADECIMIENTOS}

El autor desea agradecer a múltiples colegas y colaboradores del INIDEP, por los trabajos conjuntos en las campañas en los barcos de investigación pesquera de este Instituto y las tareas de laboratorio, particularmente al Dr. L.B. Prenski por los datos facilitados. Por los dibujos al señor Domingo Figueroa y especialmente al señor José L. Swidzinski por los trabajos de computación. También el autor agradece a dos evaluadores anónimos que han contribuido a mejorar la presentación del trabajo.

\section{REFERENCIAS}

Angelescu, V. 1960. Operación centolla en el Atlántico Sur. Serv. Hidrografía Naval. Argentina, H1013: $71 \mathrm{pp}$.

Angelescu, V. y E.E. Boschi. 1959. Estudio biológico pesquero del langostino de Mar del Plata, en conexión con la Operación Nivel Medio. Servicio Hidrografía Naval, H1017: 135.

Balech, E. 1986. De nuevo sobre la oceanografía frente a la Argentina. Servicio Hidrografía Naval, Argentina, H645: 23 pp.

Balech, E. 1971. Notas históricas y críticas de la oceanografía biológica argentina. Servicio Hidrografía Naval Argentina, H1027: 55 pp.

Bertuche, D., J. Wyngaard, C. Fischbach y E.E. Boschi. 1985. El recurso langostino del golfo San Jorge y litoral patagónico. Informe Preliminar de los resultados de las campañas de investigación pesquera del langostino en el Mar Patagónico Argentino. Presentado a CAPECA, junio 1985. Informe Téc. INIDEP, Mar del Plata, 17: 42 pp.

Bertuche, D.A., J.G. Wyngaard, C.E. Fishbach y E.E. Boschi. 1990. Population structural variation of the southern king crab, Lithodes santolla, of the Beagle Channel, Argentina, from 1975 to 1989. In: B. Melteff (ed). Proc. Int. Symp. king and Tanner Crabs, Anchorage, Alaska, 411-426.

Bertuche, D.A., J.G. Wyngaard y E.E. Boschi. 1985. The fishery biology of Beagle channel king crab (Lithodes antarcticus). In: B. Melteff (ed). Proc. Int. King Crab. Symp. Anchorage, Alaska, pp. 249-265.

Bertuche, D.A., J.G. Wyngaard, H. Hack, H. Abal y D.R. Hernández. 1987. Bioeconomic model for the argentine shrimp (Pleoticus mulleri) fishery of the San Jorge gulf, Argentina. Proc. International Conf. Fish. Univ. Quebec, Canada, 395-419.

Boschi, E.E. 1969. Estudio biológico pesquero del camarón Artemesia longinaris Bate de Mar del Plata. Bol. Inst. Biol. Marina, Mar del Plata, 18: 1-47.

Boschi, E.E. 1986. La pesquería del langostino del litoral patagónico. Revista Redes, 20: 8 pp.

Boschi, E.E. 1989. Biología pesquera del langostino del litoral patagónico de Argentina. Contrib. INIDEP Mar del Plata, 646: 71 pp. 
Boschi, E.E. y M. Mistakidis. 1966. Resultados preliminares de las campañas de pesca exploratoria del langostino y el camarón en Rawson. CARPAS Doc. Téc., 6: 1-15.

Boschi, E.E. y M.A. Scelzo. 1977. Desarrollo larval y cultivo del camarón comercial de Argentina Artemesia longinaris Bate (Crustacea, Decapoda, Penaeidae). FAO Inf. Pesca, 159(1): 187-327.

Boschi, E.E., D.A.Bertuche y J.G. Wyngaard. 1984. Estudio biológico pesquero de la centolla (Lithodes antarcticus) del Canal Beagle, Tierra del Fuego, Argentina, Contrib. INIDEP, Mar del Plata, 441: $70 \mathrm{pp}$.

Boschi, E.E., M.A. Scelzo y R. Pérez Habiaga. 1975-1976. Informes de trabajo relativos al estudio biológico pesquero de la centolla del Canal Beagle. Inst. Biol. Marina, Mar del Plata, I: 15 pp.; II, 11 pp.; III 7 pp.; IV: 6 pp.

Carriquiriborde, L.E. 1984. Ecología poblacional de camarones del litoral patagónico: Ecología y pesquería del camarón Artemesia longinaris Bate, en Bahía Engaño, Chubut. Tesis doctoral, Fac. Cienc. Nat. y Museo, Univ. Nacional de la Plata, 92 pp.

Codignoto, J.O., O. Cesari y C.A. Beros. 1990. Morfocronología secuencial evolutiva holocena en Bahía Solano, Chubut. Asoc. Geol. Argent. Rev., 45(3-4): 205-212.

Christiansen, E.HG. y M.A. Scelzo. 1971. Ciclo de maduración sexual y observaciones sobre la morfología de aparato genital del camarón Artemesia longinaris Bate (Resultados preliminares), CARPAS, 5, Doc, Téc., 16: 1-22.

Dirección General de Recursos Naturales (DGRN). 1995. Estado actual de la legislación y manejo de los recursos centolla (Lithodes santolla) y centollón (Paralomis granulosa) en el Canal Beagle. Dir. Gral. Recurs. Nat, Prov. de Tierra del Fuego, Antar. e Islas Atlant. Sur, Argentina, 19 pp.

Fenucci, J.L., C. Virasoro, M.B. Cousseau y E.E. Boschi. 1974. Campaña Tierra del Fuego 74, Informe preliminar. Contrib. Inst. Biol. Marina, Mar del Plata, 261: 37 pp.

Fenucci, J.L. y E.E. Boschi. 1975. Contribución al conocimiento del cangrejo comercial de las aguas costeras de la provincia de Buenos Aires, Ovalipes trimaculatus (de Haan) (Crustacea, Decapoda, Portunidae). Physis A (Buenos Aires), 34(89): 291308.
Hart, T.J. 1946. Report on trawling survey of the Patagonian continetal shelf. Discovery Report, Cambridge, 23: 223-408.

Labon, A. 1981. Pesca acompañante del camarón. Un regalo del mar. FAO, Roma, IDRS, 198: 175 pp.

Lovrich, G.A. 1991. Reproducción y crecimiento del centollón Paralomis granulosa (CrustaceaAnomura, Lithodidae) en el Canal Beagle. Tesis doctoral, Fac. Cienc. Exact. y Nat., Univ. Buenos Aires, 160 pp.

Lovrich, G.A. 1994. Evolution of an unmanaged crab resource in South America: The false southern king crab Paralomis granulosa. Workshop Proceeding, Moncton, New Brunswick, Canada, Can. Ms. Fish. Aquatic Sc., 62-70.

Lovrich, G.A. y J.H. Vinuesa. 1992. Información biológica y recomendaciones para el manejo de la pesquería del centollón en el Canal Beagle, Tierra del Fuego. Contribución Científica del CADIC Ushuaia, 14: $18 \mathrm{pp}$.

Lovrich, G.A. y J.H. Vinuesa. 1993. Reproductive biology of the false southern king crab (Paralomis granulosa, Lithodidae) in the Beagle Channel, Argentina. US Fish. Bull., 91(4): 664-675.

Lovrich, G.A. y J.H. Vinuesa. 1995. Growth of inmature false southern king crab Paralomis granulosa (Anomura, Lithodidae) in the Beagle Channel, Argentina. Scientia Marina, 59: 87-94.

Nascimiento, P.A.M. 1980. Binomia de Artemesia longinaris Bate, 1888 (Crustacea, Decapod Penaeidae) das aguas neríticas do Estado do Rio Grande do Sul (Lat. $29^{\circ} \mathrm{S}-35^{\circ} \mathrm{S}$ ), Brasil em 1972. Tesis doctoral, Inst. Biociencias, Univ. de São Paulo, Brasil, 200 pp.

Orozco, F.E. y J.I. Carreto, 1989. Distribution of Alexandrium excavatum resting cysts in a patagonian shelf area (Argentina). Red Tides: Biology, Environmental Science and Toxicology (Okaichi, Anderson and Nemoto, Ed.), pp. 309-312.

Petriella, A.M. y R.J. Bridi. 1992. Variaciones estacionales del ciclo de muda y la maduración ovárica del camarón Artemesia longinaris. Frente Marítimo, 11(A): 85-92.

Revista Redes. 1995. Sin rigor no hay futuro. Revista Redes, Argentina, 9(86): 50-56. 
Ruffino, M.L. 1991. Dinámica populacional do camarao Artemesia longinaris Bate, 1888 (Decapoda, Penaeidae) do sul do Brasil. Tesis de Maestria, Univ. do Rio Grande, Departamento de Oceanografía, R.G., Brasil,pp.

Ruffino, M.L. y J.P. Castello. 1992. Dinámica poblacional del camarón (Artemesia longinaris) del sur de Brasil. Frente Marítimo, 12(A): 71-81.

Sarlo, E.G. 1995. Desarrollo embrionario de Pleoticus muelleri Bate, 1888 (Crustacea, Decapoda, Solenoceridae) en condiciones de laboratorio. Efecto de la temperatura. Tesis de Licenciatura, Fac. de Ciencias Exactas y Naturales, Univ. Nacional de Mar del Plata, Argentina, 43 pp.

Scelzo, M.A., J.L. Fenucci, E.E. Boschi y A. Valentini. 1974. Centolla. Diagnóstico biológico pesquero. Informe Inédito, Consejo Federal Invers., Mar del Plata, $45 \mathrm{pp}$.

Severov, D.N. 1990. Particularidades de las condiciones oceanográficas del Atlántico Sudoccidental sobre la base de características temporales medias procedentes de una serie de años. Frente Marítimo, 6(A): 109-119.

Servicio Nacional de Pesca (SERNAPESCA). 1995. Anuario Estadístico de Pesca 1994. Minist. de Economía, Fomento y Reconstrucción, Chile, 236 pp.
Sinclair, M. 1988. Marine populations. An essay of population regulation and speciation. Washington Sea Grant Program., Univ. Washington Press, Seattle, $252 \mathrm{pp}$.

Vinuesa, J.H. 1984. Sistema reproductor, ciclo y madurez gonadal de la centolla (Lithodes antarcticus) del Canal Beagle. Contrib. INIDEP, Mar del Plata, 441: 74-92.

Vinuesa, J.H. y G.A. Lovrich. 1992. Biología y pesca de la centolla en el Canal Beagle, Tierra del Fuego, Argentina. Recomendaciones para su manejo. Contribución Científica CADIC, Ushuaia, 15: 26 pp.

Vinuesa, J.H. 1985. Differential aspects of the southern king crab (Lithodes antarcticus). Proc. Int. King Crab Symp. (Melteff, B. De.), Anchorage, Alaska, USA, 267-279 pp.

Wyngaard, J.G. y D.A. Bertuche. 1982. Algunos aspectos de la biología pesquera del langostino (Pleoticus muelleri) de la Bahía Blanca y un análisis del desembarco comercial en el período 1955-1979. Rev. Investigación y Desarrollo Pesquero, Mar del Plata, 3: 59-76. 